\title{
Nueve especies nuevas del género Sticta (Ascomycota liquenizados: L obariaceae) del morfotipo fuliginosa sensu lato de Colombia
}

\author{
Bibiana M oncada ${ }^{1, *}$, A lejandra Suárez ${ }^{2}$, R obert L ücking ${ }^{3}$ \\ ${ }^{1}$ Licenciatura en Biología, Universidad Distrital Francisco José de Caldas, Bogotá, Colombia \\ ${ }^{2}$ Facultad de Medio Ambiente y Recursos Naturales, Universidad Distrital Francisco José de Caldas, Bogotá, Colombia \\ ${ }^{3}$ Science and Education, The Field Museum, Chicago, Illinois, Estados Unidos
}

\begin{abstract}
Resumen
Como parte de una revisión taxonómica y sistemática del género Sticta en Colombia, se describen nueve especies nuevas correspondientes al morfotipo de Sticta fuliginosa: Sticta arbusculotomentosa Moncada \& Betancourt sp nov., Sticta gallowayana Moncada \& Lücking sp. nov., Sticta globulifuliginosa Moncada \& Lücking sp. nov., Sticta hirsutofuliginosa Moncada \& Lücking sp nov., Sticta jaguirreana Moncada \& Lücking sp. nov., Sticta macrofuliginosa Moncada \& Lücking sp. nov., Sticta minutula Moncada \& Lücking sp. nov., Sticta phyllidiofuliginosa Moncada \& Lücking sp. nov., y Sticta plumbeociliata Moncada \& Lücking sp. nov. Todas las especies se discuten e ilustran. Se agrega una clave para las especies del morfotipo de $S$. fuliginosa presentes en Colombia.
\end{abstract}

Palabras clave: Andes, Costa Rica, filidios, isidios, lobulillos, región Andina.

Nine new species of the genus Sticta (A scomycota liquenizados: Lobariaceae) of the fuliginosa sensu lato morphodeme from Colombia

\begin{abstract}
A bstract
As part of a taxonomic and systematic revision of the genus Sticta in Colombia, nine species corresponding to the Sticta fuliginosa morphodeme are described as new: Sticta arbusculotomentosa Moncada \& Suárez sp nov., Sticta gallowayana Moncada \& Lücking sp. nov., Sticta globulifuliginosa Moncada \& Lücking sp. nov., Sticta hirsutofuliginosa Moncada \& Lücking sp nov., Sticta jaguirreana Moncada \& Lücking sp. nov., Sticta macrofuliginosa Moncada \& Lücking sp. nov., Sticta minutula Moncada \& Lücking sp. nov., Sticta phyllidiofuliginosa Moncada \& Lücking sp. nov., and Sticta plumbeociliata Moncada \& Lücking sp. nov. All species are discussed and illustrated. A key to the species of the $S$. fuliginosa morphodeme in Colombia is provided.
\end{abstract}

K ey words: Andes, Andean region, Costa Rica, isidia, lobules, phyllidia.

\section{Introducción}

El género Sticta pertenece a la familia Lobariaceae, siendo hasta el momento el género con mayor número de especies de esta familia. Por la presencia de cifelas en la superficie ventral es uno de los géneros de macrolíquenes más fácilmente reconocidos en el mundo (G alloway, 1994, 1997, 1998a, 2001, 2007, M cD onald, et al., 2003, M oncada, 2012), aunque no debe confundirse con el género Dendriscosticta, nombre recientemente asignado a un conjunto de especies del hemisferio norte del grupo de Sticta wrightii relacionado cercanamente con los géneros Lobariella y Lobaria s. lat. (M oncada, et al., 2013a). Sticta puede tener cianobacterias o algas verdes como fotobiontes primarios o, en ocasiones, la misma especie forma un cloromorfo y un cianomorfo (Purvis, 2000; Tønsberg \& G oward, 2001, Takahashi, et al., 2006, M oncada, et al., 2013c). Tiene una distribución cosmopolita, aunque está mejor representado en regiones tropicales (J oshi \& Awasthi, 1982, Swinscow \& K rog, 1988, Galloway, 1998b, Büdel, et al., 2000, A ptroot \& Sparrius, 2002, Farkas,2003). En Suramérica el género se encuentra principalmente en la zona subandina y andina, sobre varios sustratos como corteza, madera, rocas, suelo y troncos en descomposición (G alloway, 1997, M oncada, et al., 2014).

Hasta la fecha, las especies de Sticta presentes en el territorio colombiano eran poco conocidas. Luteyn (1999) hizo referencia a diez especies en las regiones paramunas y Sipman, et al. (2000) reconocieron 18 especies y una

\footnotetext{
* Correspondencia:

Bibiana Moncada; bibianamoncada@gmail.com

Recibido: 7 de septiembre de 2014

A ceptado: 11 de febrero de 2015
} 
variedad para estas áreas. Aguirre-C (2008) presentó un total de 29 especies y mencionó a Sticta como un género mayormente andino, lo que fue confirmado por los estudios de Moncada, et al., (2014). Sipman, et al. (2008) dieron a conocer un total de 42 nombres para Colombia. Sin embargo, este número solo cubre una pequeña parte de la diversidad real, ya que en una primera revisión monográfica, M oncada (2012) mencionó al menos 103 especies para el territorio colombiano. Este estudio se basó en un análisis de filogenia molecular (M oncada, et al., 2013b) y una revisión de material tipo de más de 160 nombres descritos para el Neotrópico y otras partes del mundo, lo cual indica que una gran parte de estas especies son nuevas para la ciencia.

El morfotipo de la especie Sticta fuliginosa (Dicks.) Ach. es, probablemente, el de más fácil reconocimiento dentro del género. Es así como, en general, se puede asegurar que representan ejemplares con talos orbiculares de tamaños reducidos, menores a $10 \mathrm{~cm}$ de diámetro, caracterizados por asociarse con un fotobionte cianobacterial, tomento inferior claro, cifelas grandes, en su mayoría planas, y por sus isidios laminales para la propagación vegetativa. En su anatomía se reconoce su médula rala, blanca con reacciones negativas a K, KC, C y P, aunque G yelnik (1931), mencionó que $S$. fuliginosa poseía una médula " $\mathrm{K}+$ rufuscens y $\mathrm{KC}+$ rosea", además de mencionar los apotecios esparcidos en su superficie dorsal. Generalmente, el material con esta combinación de caracteres ha sido considerado como una sola especie con distribución cosmopolita (H ue, 1901; G alloway, 1994, 1997, 1998a, 2001, 2007; Stizenberger, 1895). Sin embargo, varios estudios moleculares han demostrado que se trata de un morfotipo que evolucionó muchas veces en el género Sticta, en clados distantes, así que en realidad se trata de muchas especies diferentes que comparten una morfología y, en algunos casos, una ecología semejante (M oncada, et al., 2013b).

En la revisión filogenética del género Sticta para Colombia (M oncada, et al., 2013b), se incluyó una muestra considerada como un topotipo de $S$. fuliginosa, así que el clado que contenía dicha muestra, con especímenes adicionales de Colombia, Norteamérica y Europa, fue denominado $S$. fuliginosa s.str. Sin embargo, la revisión del material tipo de S. fuliginosa hecha por Magain \& Sér usiaux (comunicación personal, 2014) reveló que en la localidad tipo ocurren al menos dos especies diferentes, y que el material secuenciado pertenece a una especie aún sin describir, la cual va a ser formalmente descrita en otro trabajo (Magain \& Sérus, en preparación). Por lo tanto, el nombre de esta especie se cita aquí como $S$. aff. fuliginosa.

Con la descripción de estas nueve especies del morfotipo fuliginosa para Colombia, sumadas a S. arachnofuliginosa, S. arbuscula y S. maculofuliginosa (M oncada \& L ücking, 2012b) S. ciliata (Taylor en M ackay, 1836), S. cometiella (Vainio, 1926), S. aff. fuliginosa (M again \& Sérusiaux, en preparación), S. macrothallina (cianomorfo) y $S$. neopulmonarioides (cianomorfo) (M oncada, et al., 2013c), S. roseocyphellata (M oncada, et al., en preparación) y $S$. viviana (Suárez \& L ücking, 2013), se completa un total de 19 especies con este morfotipo presentes en el país.

\section{M ateriales y métodos}

Se revisaron aproximadamente 2.200 colecciones de Sticta presentes en los herbarios colombianos ANDES, COAH, COL, CUVC, FAUC. HUA, COAH, UDBC, UPTC, así como las colecciones históricas y colecciones tipo disponibles en los herbarios internacionales B, BM, F, G, H, L, MEL, OXF, PC, RBGE, TUR, U, US y W. A la mayoría de las muestras se les hizo una revisión morfológica y anatómica en la cual se estudiaron 168 caracteres (M oncada \& L ücking, 2012b; M oncada, 2012, M oncada, et al., 2013b). La química secundaria se evaluó mediante cromatografía de capa fina utilizando los solventes A y C (Orange, et al., 2001; L umbsch, 2002). Los estudios se hicieron en los laboratorios de la Licenciatura en Biología de la Universidad Distrital Francisco José de Caldas, en Bogotá, y del Departamento de Botánica del The Field Museum, Chicago, Estados Unidos.

\section{Resultados y discusión}

\section{Sticta arbusculotomentosa M oncada \& Betancourt sp nov.}

\section{Index Fungorum IF550878}

Differing from Sticta arbuscula in the coriaceous thallus with the upper surface pubescent-arachnoid, the isidia having a tomentose stalk, and the cyphellae being smaller than $2 \mathrm{~mm}$ diam.

Tipo. COLOMBIA. Cundinamarca: Municipio de Bogotá, D.C., Parque Nacional Natural Sumapaz, alrededores de la Laguna de Chisacá, sobre Diplosthephium revolutum; 3600 m; 1 Dic 2010, L. Betancourt 326 (UDBC, holotipo). (Figura 1)

Descripción. Fotobionte primario cianobacteria. Pedúnculo ausente. Talo orbicular a irregular, hasta $10 \mathrm{~cm}$ de diámetro, poco ramificado, con 0-2 ramificaciones por $5 \mathrm{~cm}$ de radio, ramificación anisotómica. Lóbulos suborbiculares, horizontales a ascendentes, adyacentes a imbricados, planos a involutos, con los ápices redondeados a irregulares e involutos y los márgenes enteros a crenados, no engrosados; entrenudos de los lóbulos de (4-)5-17(-20) mm de largo, (5-)8-13(-15) $\mathrm{mm}$ de ancho, subcoriáceos, frágiles. Superficie superior escrobiculada a levemente acostillada, de color verde esmeralda cuando fresco, gris parduzco y con frecuencia el márgen marrón pálido en el herbario, opaca, con la línea marginal del mismo color; superficie pubescente a aracnoidea, sin papilas, sin pruina, con máculas irregulares, escasas, blancas. Cilios ausentes. Apotecios no observados. Propágulos vegetativos presentes, abundantes, en forma de isidios, principalmente laminares, agregados, ramificados, arbusculares, verticales a oblicuos, hasta de $2 \mathrm{~mm}$ de largo y $1 \mathrm{~mm}$ de ancho, más oscuros que el talo, de color marrón negruzco, brillantes, en sección transversal redondos a 

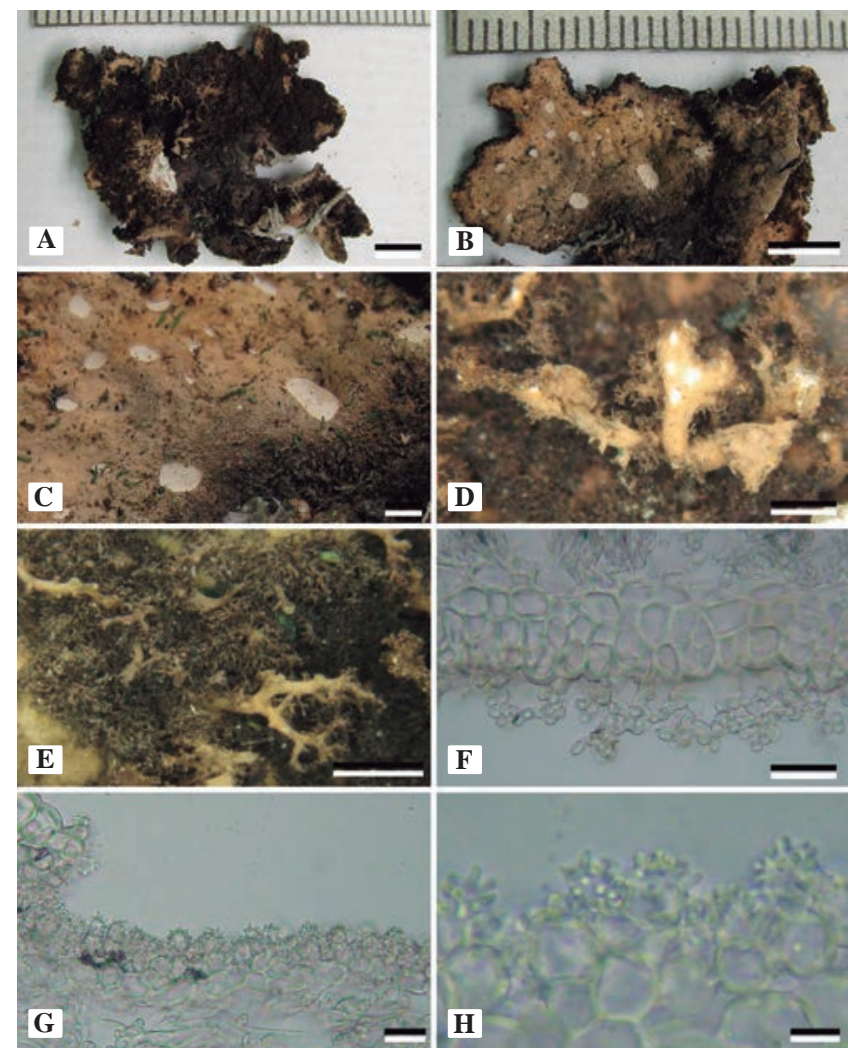

Figura 1. Sticta arbusculotomentosa. A. Vista de la superficie dorsal del talo. B. Superficie ventral del talo. C. Detalle de las cifelas y del tomento ventral. D. Detalle de los isidios arbusculares con cifelas. E. Detalle del tomento en los isidios arbusculares. F. Detalle del tomento ventral secundario. G-H. Cifela y cifeloblastos con papilas abundantes. Escala: A-B $=5 \mathrm{~mm}, \mathrm{C}-\mathrm{E}=1 \mathrm{~mm}, \mathrm{~F}=30$ $\mu \mathrm{m}, \mathrm{G}=50 \mu \mathrm{m}, \mathrm{H}=20 \mu \mathrm{m}$

levemente aplanados, cilíndricos a espatulados; pedúnculo si presente, cilíndrico, con cifelas y tomento. Médula laxa a compacta, de color blanco, $\mathrm{K}+$ amarillo pálido a ocre, $\mathrm{C}-, \mathrm{KC}+$ amarillo pálida a ocre. Superficie inferior lisa a ondulada, de color blanco-crema, oscureciéndose hacia el centro. Tomento ventral principal inferior irregular, ausente hacia el margen, grueso (largo), fasciculado a esponjoso, suave, de color gris marrón pálido a oscuro. Tomento ventral secundario pubescente, claro. Rizinas ausentes. Cifelas escasas, 1-20 por $\mathrm{cm}^{2}$ hacia el centro del talo y 21-40 por $\mathrm{cm}^{2}$ hacia el margen, dispersas, redondeadas a irregulares, urceoladas con poro ancho a cupuliformes, inmersas a erumpentes, abajo del nivel del tomento, con el margen indiferenciado a levemente involuto de color blanco crema, con tomento secundario; poro de $(0,1-) 0,3-1(-1,5)$ $\mathrm{mm}$ de diámetro hacia el centro del talo; membrana basal pubescente, de color blanco, $\mathrm{K}-\mathrm{a} \mathrm{K}+$ amarillo pálido, $\mathrm{C}-$, $\mathrm{KC}+$ amarillo pálido, $\mathrm{P}-$. Picnidios no observados.

Corteza superior paraplectenquimática, de 25-40 $\mu \mathrm{m}$ de grosor, homogénea, conformada por $2-3$ capas de células, de 6-16 $\mu \mathrm{m}$ de diámetro, con la pared de 1,2-2,5 $\mu \mathrm{m}$ de grosor y el lumen redondeado a isodiamétrico de 5-15 $\mu \mathrm{m}$ de diámetro. Capa de algas de 25-45 $\mu \mathrm{m}$ de grosor, con las células de 12-18 $\mu \mathrm{m}$ de diámetro. Médula de 65-210 $\mu \mathrm{m}$ de grosor, con hifas de $2,5 \mu \mathrm{m}$ de ancho, sin cristales. Corteza inferior paraplectenquimática, de 30-40 $\mu \mathrm{m}$ de grosor, con 1-2 capas de células; células de 6-18 $\mu \mathrm{m}$ de diámetro, con la pared de $1,2-2,5 \mu \mathrm{m}$ de grosor. Tomento dorsal principal de 7-20 $\mu \mathrm{m}$ de largo, solitario, hifas ramificadas, moniliformes con los ápices libres Tomento ventral principal de 300-850 $\mu \mathrm{m}$ de largo, en fascículos de 12-20 hifas, hifas ramificadas, apicalmente moniliformes con los ápices libres. Tomento ventral secundario presente, de 10-25 $\mu \mathrm{m}$ de largo, solitario, hifas ramificadas, moniliformes con los ápices libres. Cavidad de las cifelas 30-80 $\mu \mathrm{m}$ de alto; células de la membrana basal de la cifela (cifeloblastos) con abundantes papilas.

E timología. Esta especie recibe su nombre por los isidios arbusculares con pedúnculos tomentosos y la superficie dorsal pubescente aracnoide.

Distribución y ecología. Andes de Colombia. Se ha encontrado entre 2.600 y $3.600 \mathrm{~m}$, sobre corteza en lugares cerrados o en ramas secundarias con baja exposición solar, junto con hepáticas de los géneros Frullania, Metzgeria, Plagiochila y Radula. Se cuenta únicamente con dos registros que comprenden las zonas de vida subandina y de páramo de la región andina colombiana, en los departamentos de Antioquia y Cundinamarca.

Discusión. Sticta arbusculotomentosa es una de las pocas especies del género con isidios arbusculares, es decir con un pedúnculo pronunciado. Además, se caracteriza por presentar talos irregulares o menos frecuentemente, suborbiculares, con la superficie dorsal lisa a acostillada, pubescente aracnoidea, pero no escabrosa como en $S$. arbuscula Moncada \& Lücking (Moncada \& Lücking, 2012b). Los arbúsculos son laminares, robustos y hasta de 2 mm de longitud, con pedúnculos tomentosos y gruesos hasta de $1 \mathrm{~mm}$ de diámetro. Sticta arbuscula también produce isidios arbusculares, pero tiene un talo orbicular, pubescente a escabroso, con arbúsculos mayormente marginales y sin tomento. Las cifelas también son un carácter que ayuda a separar las especies, debido a que son menores de $2 \mathrm{~mm}$ en S. arbusculotomentosa y hasta de 3,5 $\mathrm{mm}$ en S. arbuscula.

E specímenes examinados. COLOMBIA. Antioquia: Municipio de Santa Rosa de Osos, Llanos de Cuiva; 2.600 m; 10 de abril, 1992, F. Pineda 654 (HUA). Cundinamarca: Municipio de Choachí, Parque Matarredonda; 3.351 m; 27 de noviembre, 2014, Moncada 8822 (UDBC).

\section{Sticta gallowayana M oncada \& L ücking sp. nov.}

\section{Index Fungorum IF550805}

Differing from Sticta aff. fuliginosa in the strongly branched, corymbose ('broccoliform') isidia and the lack of papillae on the cells of the basal membrane of the cyphellae. 
Tipo. COLOMBIA. Cundinamarca: Municipio de La Calera, Parque Nacional Natural Chingaza, Monterredondo; $4^{\circ} 44^{\prime}$ N, $73^{\circ}$ 51' O; 3.430 m; 13 de abril, 2011, B. Moncada 4637 (UDBC, holotipo; COL, F, CUCV, isotipos). (Figura 2)

Descripción. Fotobionte primario cianobacteria. Pedúnculo ausente. Talo orbicular a irregular, hasta de $10 \mathrm{~cm}$ de diámetro, poco ramificado, con 0-2 ramificaciones por 5 $\mathrm{cm}$ de radio, ramificación politómica. Lóbulos suborbiculares, horizontales, imbricados, ondulados, con los ápices redondeados, revolutos, márgenes enteros a crenados, no engrosados; entrenudos de los lóbulos de 10-20 mm de largo, (5-)8-12(-18) $\mathrm{mm}$ de ancho, subcoriáceos, frágiles. Superficie superior escrobiculada a costillada, de color verde oscuro cuando fresco, gris verdoso con bordes marrón en el herbario, poco brillante, con la línea marginal del mismo color; superficie glabra, sin papilas, sin pruina, con máculas irregulares, blancas. Cilios ausentes. Apotecios no observados. Propágulos vegetativos presentes, abundantes, en forma de isidios, principalmente laminares, agregados, ramificados, corimbosos, verticales, hasta de $2 \mathrm{~mm}$ de largo y $0,2-0,5 \mathrm{~mm}$ de ancho, más oscuros que el talo, opacos, en sección transversal redondos, cilíndricos; pedúnculo si presente, cilíndrico a levemente aplanado en

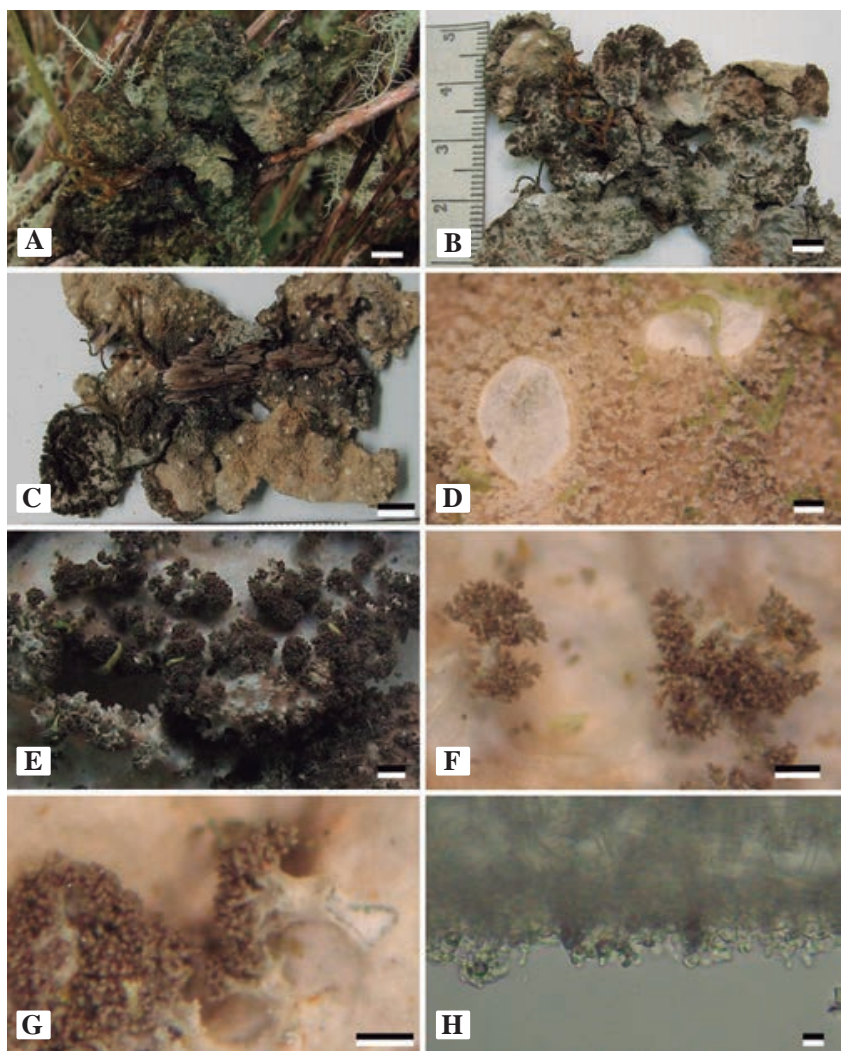

Figura 2. Sticta gallowayana. A. Vista dorsal del talo en vivo. B. Vista dorsal del talo en seco. C. Vista ventral del talo. D. Detalle de las cifelas y del tomento ventral. E-G. Detalle de los isidios corimbosos. H. Cifeloblastos con una papila. Escala: A-C $=5 \mathrm{~mm}$, $\mathrm{D}-\mathrm{G}=1 \mathrm{~mm}, \mathrm{H}=10 \mu \mathrm{m}$. isidios viejos, sin cifelas. Médula laxa, de color blanco, $\mathrm{K}-$, $\mathrm{C}-, \mathrm{KC}-, \mathrm{P}-$. Superficie inferior ondulada, de color crema. Tomento ventral principal denso hasta el margen, grueso (largo), esponjoso a fasciculado, suave, de color crema, oscureciéndose hacia el centro. Tomento ventral secundario ausente. Rizinas ausentes. Cifelas escasas, $1-10$ por $\mathrm{cm}^{2}$ hacia el centro del talo y $1-20$ por $\mathrm{cm}^{2}$ hacia el margen, dispersas, irregulares, urceoladas con poro ancho, inmersas a erumpentes, abajo del nivel del tomento, con el margen levantado e involuto de color crema, sin tomento; poro de $(0,3-) 0,5-2(-3) \mathrm{mm}$ de diámetro hacia el centro del talo; membrana basal pube-scente, de color blanco, $\mathrm{K}-\mathrm{a} \mathrm{K}+$ amarillo pálido, $\mathrm{C}-, \mathrm{KC}+$ amarillo pálido, $\mathrm{P}-$. Picnidios no observados.

Corteza superior paraplectenquimática, de 20-30 $\mu \mathrm{m}$ de grosor, homogénea, conformada por 3-4 capas de células, de 3-6 $\mu \mathrm{m}$ de diámetro, con la pared de $0,6-1 \mu \mathrm{m}$ de grosor y el lumen redondeado a isodiamétrico de $1,2-5 \mu \mathrm{m}$ de diámetro. Capa de algas de 30-70 $\mu \mathrm{m}$ de grosor, con las células de 12-20 $\mu \mathrm{m}$ de diámetro. Médula de $80-150 \mu \mathrm{m}$ de grosor, con hifas de 2,5 $\mu \mathrm{m}$ de ancho, sin cristales. Corteza inferior paraplectenquimática, de 20-30 $\mu \mathrm{m}$ de grosor, con 2-3 capas de células; células de 4-8 $\mu \mathrm{m}$ de diámetro, con la pared de $0,6-1 \mu \mathrm{m}$ de grosor. Tomento ventral principal de 165-260 $\mu \mathrm{m}$ de largo, en fascículos de 6-12 hifas, hifas simples, septadas con los ápices libres. Cavidad de las cifelas de 180-220 $\mu \mathrm{m}$ de alto; células de la membrana basal sin papilas.

E timología. Esta especie recibe su nombre en honor del Dr. David Galloway (recién fallecido), especialista en el grupo, en reconocimiento por sus grandes aportes al estudio del género Sticta en el mundo.

Distribución y ecología. Andes de Colombia. Se ha encontrado entre $2.100-4.285 \mathrm{~m}$, ampliamente distribuida en bosques subandinos, andinos y páramos, en lugares con intensidad lumínica media a alta. Se cuenta con registros procedentes de las cordilleras Central y Occidental, en hábitats de subandinos a páramo. Crece sobre diversos sustratos como corteza, roca, suelo y troncos, generalmente asociada con especies de los géneros Frullania, Metzgeria y Lepicolea.

Discusión. Sticta gallowayana es otra especie segregada de la especie colectiva $S$. fuliginosa, de la que se distingue principalmente por sus isidios corimbosos, superficie dorsal glabra, con máculas blancas irregulares, sin cilios ausentes y por la ausencia de papilas en los cifeloblastos. Otra especie con isidios de esta forma es $S$. viviana (Suárez \& Lücking, 2013), que forma talos mucho más pequeños con la médula K+ amarilla-naranja y un tomento inferior secundario presente.

Especímenes examinados. COLOMBIA. Arauca: Municipio de El Playón, Parque Nacional Natural El Cocuy, Nevado del Cocuy, cabecera de la quebrada El Playón, Patio Bolos; 4.285 m; 7 de marzo, 1973, A. M. Cleef 8849 (COL, U). Boyacá: Municipio de Cucaita, a 10 km de Tunja; 2.950 m; 
12 de julio, 1986, H. Sipman \& O. Reyes 34476 (B, COL). Municipio de Villa de Leyva, SFF Iguaque, Caseta de administración a Villa de Leyva; 2.800 m; 25 de mayo, 2000, B. Moncada \& R. Dávila 870 (UDBC). SFF Iguaque, sector El Carrizal; 2.100-2.900 m; 9 de junio, 2001, E. Linares, et al. 9630 (COL). Caldas: Municipio de Aranzazú, vereda El Diamante, Finca El Porvenir; $75^{\circ} 26^{\prime} \mathrm{O}, 5^{\circ} 15^{\prime} \mathrm{N}$; 2.600 m; 2010, L. F. Coca 85s (UDBC). Municipio Villa María, Nevado del Ruíz, Noroccidente de termales, abajo del hotel; 3.500 m; 4 de febrero, 1979, H. Sipman \& H. Valencia 10533 (COL). Cundinamarca: Municipio de Bogotá, D.C., Parque Nacional Natural Sumapaz, proximidades de Laguna Grande; 3.700 m; 4 de septiembre, 1984, J. Aguirre \& H. Sipman 5006 (B, COL); ibid.; 3.500 m; 14 de julio, 1986, H. Sipman, et al. 34502 (B, COL). Alrededores de la Laguna de Chisacá; $4^{\circ} 17^{\prime} \mathrm{N}, 7^{\circ} 12^{\prime}$ O; 3724 m; 15 de agosto, 2010, B. Moncada, et al. 3999, 4013, 4036, 4099, 4140 (UDBC). Municipio de Fómeque, Parque Nacional Natural Chingaza, sendero La Arboleda; 3.060 m; 12 de mayo, 2003, B. Moncada \& R. Dávila 1621 (UDBC). Municipio de La Calera, Parque Nacional Natural Chingaza, Monterrendodo; $4^{\circ} 44^{\prime}$ N, 73 51’ O; 3.430 m; 13 de abril, 2011, B. Moncada 4636, 4637 (UDBC). Zona de amortiguación del Parque Nacional Natural Chingaza, Vía del ángulo al Rincón del Oso; 3.600 m; 7 de noviembre, 2011, B. Moncada 4903, 4974 (UDBC). Municipio de Supatá, Alto El Tablazo, carretera Estación Radar a Supatá; 3.400 m; 12 de septiembre, 1985, J. Aguirre \& H. Sipman 5273 (B, COL). Risaralda: Municipio de Santa Rosa de Cabal, Valle de la Quebrada Betania, Hacienda La Sierra; 3.755 m; 25 de enero, 1980, T. Boekhout $332 b$ (COL). Tolima: Municipio de Santa Isabel, Valle del Río Totarito, margen izquierda del Río; 3.730 m; 6 de febrero, 1980, H. Valencia \& T. Boekhout 52 (B, COL). Valle del Río Totarito. Entre el Paso Español y Hacienda La Ermita; 3.650 m; 9 de febrero, 1980, H. Valencia \& T. Boekhout 154 (COL).

\section{Sticta globulifuliginosa M oncada \& L ücking sp. nov.}

\section{Index Fungorum IF550806}

Differing from Sticta aff. fuliginosa in the usually larger thallus and lobes producing short, subglobose isidia, and in the absence of papillae on the cells of the basal membrane.

Tipo. COLOMBIA. Cundinamarca: Municipio de Guasca, Páramo de Guasca; 3.350 m; 18 de agosto, 2011, B. Moncada 4757 (UDBC, holotipo; COL, F, isotipos). (Figura 3)

Descripción. Fotobionte primario cianobacteria. Pedúnculo ausente. Talo orbicular a irregular, hasta de $10 \mathrm{~cm}$ de diámetro, poco ramificado, con $0-2$ ramificaciones por $5 \mathrm{~cm}$ de radio, ramificación politómica. Lóbulos suborbiculares, horizontales, imbricados, planos a revolutos, con los ápices redondeados, revolutos, márgenes enteros a lacerados, no engrosados; entrenudos de los lóbulos de 11-25 mm de largo, (5-)7-20(-35) mm de ancho, papiráceos a subcoriáceos, frágiles. Superficie superior escrobiculada a levemente foveolada o subfaveolada, de color marrón verdoso cuando

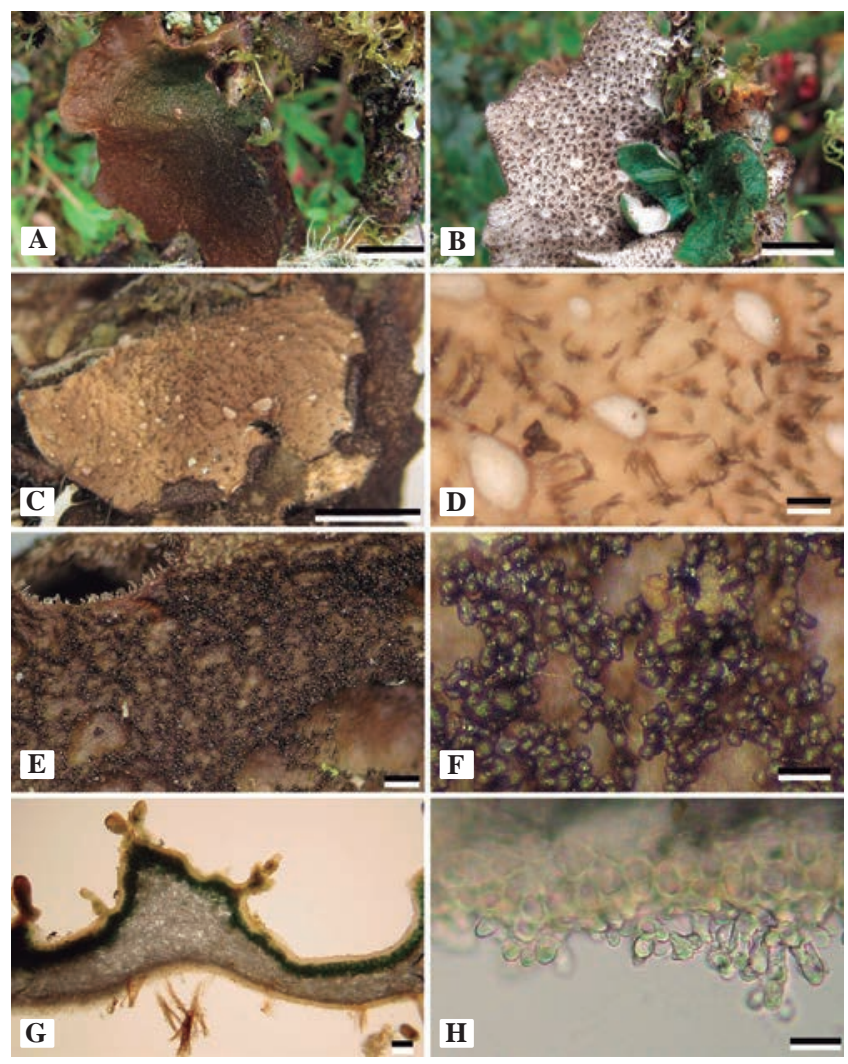

F igura 3. Sticta globulifuliginosa. A. Vista dorsal del talo en vivo. B. Vista ventral del talo en vivo. C. Superficie ventral. D. Detalle del tomento ventral y de las cifelas. E-F. Detalle de los isidios laminares. G. Anatomía del talo. H. Cifeloblastos. Escala: A-C $=1$ $\mathrm{cm}, \mathrm{D}-\mathrm{F}=0,5 \mathrm{~mm}, \mathrm{G}=100 \mu \mathrm{m}, \mathrm{H}=25 \mu \mathrm{m}$

fresco, marrón oscuro en el herbario, brillante, con la línea marginal del mismo color; superficie glabra, sin papilas, sin pruina, con máculas irregulares, blancas a cremas. Cilios escasos a ausentes pero prolongaciones del tomento inferior visibles, fasciculados, marrón pálido, hasta de $0,5 \mathrm{~mm}$ de largo. Apotecios no observados. Propágulos vegetativos presentes, abundantes, en forma de isidios, principalmente laminares, dispersos a subagregados, simples a apicalmente ramificados, verticales, hasta de $0,2 \mathrm{~mm}$ de largo y 0,2 mm de ancho, más oscuros que el talo, de color marrón a marrón negruzco, brillantes, en sección transversal redondos a levemente aplanados, globulares a cilíndricos; pedúnculo si presente, cilíndrico a levemente aplanado, sin cifelas. Médula laxa, de color blanco, $\mathrm{K}+$ amarillo pálido a ocre, $\mathrm{C}-$, KC-, P-. Superficie inferior rugosa a acostillada, de color crema. Tomento ventral principal denso, escaso hacia el margen, grueso, más delgado hacia el margen, fasciculado a esponjoso, suave, de color marrón grisáceo con los ápices blancos. Tomento ventral secundario aracnoide, claro. Rizinas ausentes. Cifelas escasas, $1-10$ por $\mathrm{cm}^{2}$ hacia el centro del talo y $21-40$ por $\mathrm{cm}^{2}$ hacia el margen, dispersas, irregulares a angulares, urceoladas con poro ancho a cupuliformes, erumpentes a suprasésiles, abajo del nivel del tomento, con 
el margen levantado e involuto de color crema a marrón, con tomento; poro de $(0,01-) 0,2-0,5(-0,7) \mathrm{mm}$ de diámetro hacia el centro del talo; membrana basal pubescente, de color blanco, $\mathrm{K}+$ amarillo, $\mathrm{C}-$ - $\mathrm{KC}+$ amarillo, $\mathrm{P}-$. Picnidios no observados.

Corteza superior paraplectenquimática, de 17-30 $\mu \mathrm{m}$ de grosor, homogénea, conformada por 2-3 capas de células, de 3-12 $\mu \mathrm{m}$ de diámetro, con la pared de $0,6-2,5 \mu \mathrm{m}$ de grosor y el lumen redondeado a isodiamétrico de 2,5-10 $\mu \mathrm{m}$ de diámetro. Capa de algas de 30-55 $\mu \mathrm{m}$ de grosor, con las células de 10-15 $\mu \mathrm{m}$ de diámetro. Médula de 30-65 $\mu \mathrm{m}$ de grosor, con hifas de 2,5 $\mu \mathrm{m}$ de ancho, sin cristales. Corteza inferior paraplectenquimática, de $12-20 \mu \mathrm{m}$ de grosor, con 1-2 capas de células; células de 6-12 $\mu \mathrm{m}$ de diámetro, con la pared de $0,6-2,5 \mu \mathrm{m}$ de grosor. Tomento ventral principal de 170-210 $\mu \mathrm{m}$ de largo, en fascículos de 6-12 hifas, hifas ramificadas, apicalmente moniliformes con los ápices entrecruzados. Tomento ventral secundario de 12-25 $\mu \mathrm{m}$ de largo, solitario, hifas ramificadas, moniliformes con los ápices libres. Cavidad de las cifelas de 70-180 $\mu \mathrm{m}$ de alto; células de la membrana basal de la cifela (cifeloblastos) con una papila.

E timología. Esta especie recibe su nombre por sus característicos isidios globulares.

Distribución y ecología. Andes de Colombia. Se ha encontrado entre $2.400-4.000 \mathrm{~m}$, en bosques andinos y de páramo, en lugares con intensidad lumínica media a alta. Se cuenta con registros procedentes de la vertiente occidental de las cordilleras Central y Oriental, en las zonas de vida andina y de páramo de la región andina colombiana. Crece sobre corteza, generalmente asociada con hepáticas del género Metzgeria y líquenes como Coccocarpia pellita, Everniastrum cirrhatum y Leptogium spp.

Discusión. Además de la ausencia de papilas en los cifeloblastos, Sticta globulifuliginosa se diferencia de $S$. aff. fuliginosa por el tamaños de los talos, que son más grandes y con isidios cortos y anchos, subglobosos, generalmente no ramificados. Estos isidios, entre otros caracteres, también la distinguen de las otras especies segredadas con talos grandes, como S. arachnofuliginosa Moncada \& Lücking (Moncada \& Lücking, 2012b), S. gallowayana (con isidios corimbosos; ver arriba), S. macrofuliginosa (con talo faveolado y apotecios; ver abajo) y S. phyllidiofuliginosa (con filidios; ver abajo).

E specímenes examinados. COLOMBIA. Boyacá: Municipio de Duitama, Páramo de La Rusia, $1 \mathrm{~km}$ al sur de Laguna Negra; 3.745 m; 15 de diciembre, 1972, A. M. Cleef 7280 (B, COL). Municipio de El Cocuy, Parque Nacional Natural El Cocuy, sendero Cabaña Sisuma rumbo a Pico Pan de Azúcar; 3.800-4.800 m; 20 de abril, 2011, D. Fonseca \& F. Martínez 104 (UDBC). Municipio de Villa de Leyva, SFF Iguaque, Caseta de administración a Villa de Leyva; 2.800 m; 29 de octubre, 2002, B. Moncada \& R. Dávila 1726 (UDBC).
Caldas: Municipio de Villa María, Nevado del Ruíz, costado noroccidental, a 500 m de la estación de televisión; 3.900 m; 3 de febrero, 1979, H. Sipman \& H. Valencia 10479 (COL). Cauca: Municipio de Puracé, Parque Nacional Natural Puracé, Pilimbalá a Laguna de San Rafael; 3.220 m; 18 de marzo, 2000, B. Moncada \& R. Dávila 502 (UDBC). Cundinamarca: Municipio de Bogotá, D.C., a 50 km NE de Bogotá, a lo largo de la carretera Guasca-Gachetá; 3.300 m; 7 de febrero, 1979, H. Sipman \& H. Valencia 10638 (COL, U). Parque Nacional Natural Sumapaz, alrededores de la Laguna de Chisacá; $4^{\circ}$ $17^{\prime}$ N, 74 12' O; 3.724 m; 15 de agosto, 2010, B. Moncada, et al. 4037, 4137b, 4241 (UDBC). Municipio de Chipaque, vereda Marilandia, vía Santuario; 2.400 m; 8 de septiembre, 2011, B. Moncada 4821 (UDBC). Municipio de Guasca, Parque Nacional Natural Chingaza, Piedras Gordas; 3.200 m; 15 de octubre, 1988, H. Sipman \& J. Aguirre 27382b (B, COL). Páramo de Guasca; 3.350 m; 18 de agosto, 2011, $B$. Moncada 4742, 4742b, 4743, 4745, 4747, 4757 (UDBC); ibid.; R. Lücking 33318, 33327 (F, UDBC). Municipio de La Calera, Parque Nacional Natural Chingaza, Monterredondo; $4^{\circ} 44^{\prime}$ N, 73 51' O; 3.430 m; 13 de abril, 2011, B. Moncada 4626 (UDBC). Municipio de Neusa, cerro oriental, represa del Neusa; 3.100 m; 3 de agosto, 1975, T. v. d. Hammen \& R. Jaramillo-M 3136b (COL). Municipio de San Francisco, vereda Sabaneta, proximidades de la quebrada Cueva Grande; 2.500 m; 17 de julio, 1986, H. Sipman, et al., 23590 (COL). Nariño: Municipio de Pasto, $10 \mathrm{~km}$ al N de Pasto, a lo largo de la carretera a Popayán; 2.550 m; 17 de junio, 1986, $H$. Sipman, R. Velosa, et al., 33618 (B, COL).

\section{Sticta hirsutofuliginosa M oncada \& L ücking sp nov.}

\section{Index Fungorum IF550807}

Differing from Sticta aff. fuliginosa in the scrobiculate to faveolate thallus with the upper surface pubescent, and the cells of the basal membrane of the cyphellae lacking papillae.

Tipo. COLOMBIA. Cundinamarca: Municipio de Guasca, Páramo de Guasca; 3.350 m; 18 de agosto, 2011, B. Moncada 4734a (UDBC, holotipo; F, CUVC, isotipos). (Figura 4)

Descripción. Fotobionte primario cianobacteria. Pedúnculo ausente. Talo orbicular a irregular, hasta de $10 \mathrm{~cm}$ de diámetro, poco ramificado, con 0-2 ramificaciones por $5 \mathrm{~cm}$ de radio, ramificación politómica. Lóbulos suborbiculares, horizontales a levemente subpéndulos, imbricados, ondulados, con los ápices redondeados a irregulares, involutos, márgenes enteros a crenados, no engrosados; entrenudos de los lóbulos de 10-30 mm de largo, (5-)8-20(-40) $\mathrm{mm}$ de ancho, subcoriáceos, resistentes. Superficie superior escrobiculada a acostillada, de color verde esmeralda cuando fresco, gris verdoso con los bordes más oscuros en el herbario, opaca, con la línea marginal del mismo color; superficie glabra o débilmente pubescente hacia el margen y con abundante tomento como setas esponjosas hacia el centro, sin papilas, sin pruina, con máculas irregulares, blancas. Cilios ausentes. Apotecios no observados. Propágulos vegetativos presentes, 

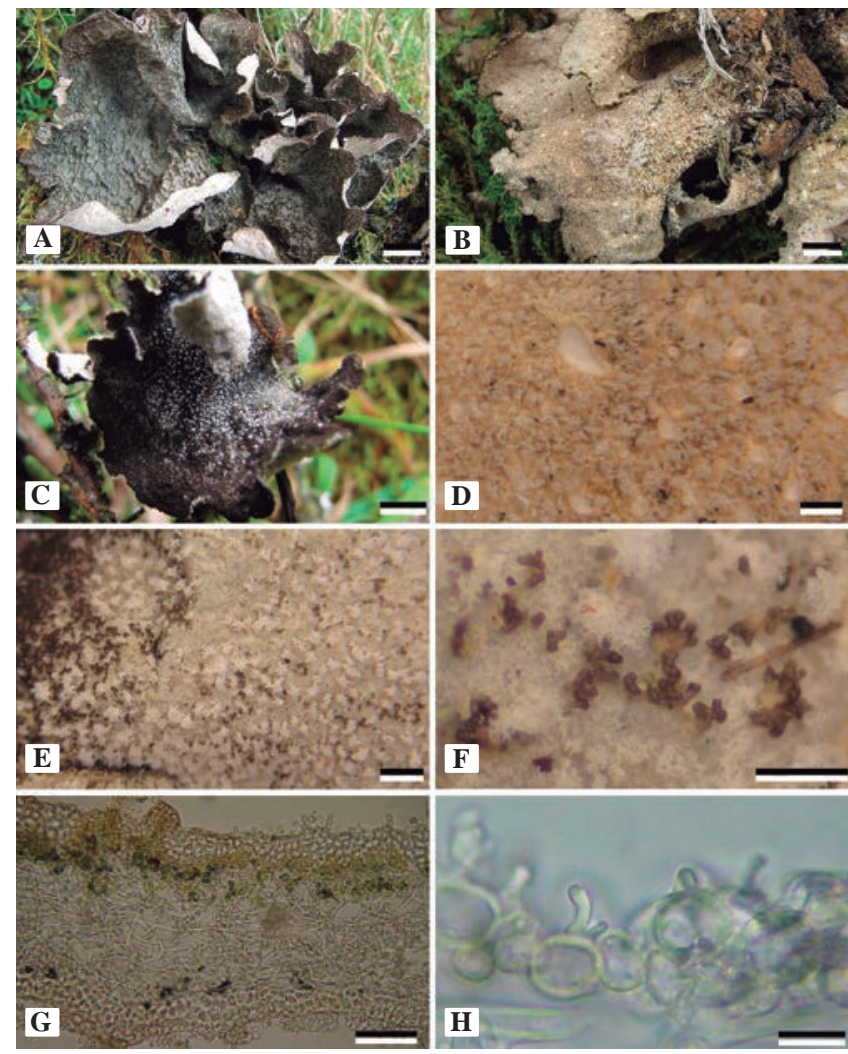

Figura 4. Sticta hirsutofuliginosa. A. Vista dorsal del talo en vivo. B. Vista ventral del talo en vivo. C. Detalle del tomento dorsal en vivo. D. Detalle del tomento ventral y de las cifelas. E. Detalle del tomento dorsal. F. Detalle de los isidios laminares. G. Anatomía del talo. H. Cifeloblastos con una papila. Escala: A-C = $1 \mathrm{~cm}, \mathrm{D}=3$ $\mathrm{mm}, \mathrm{E}-\mathrm{F}=1 \mathrm{~mm}, \mathrm{G}=100 \mu \mathrm{m}, \mathrm{H}=10 \mu \mathrm{m}$

abundantes, en forma de isidios, principalmente laminares, dispersos, simples a apicalmente ramificados, coraloides, verticales, hasta de $0,5 \mathrm{~mm}$ de largo y $0,2 \mathrm{~mm}$ de ancho, más oscuros que el talo, brillantes, en sección transversal redondos, cilíndricos; pedúnculo si presente, cilíndrico, sin cifelas. Médula laxa, de color blanco, $\mathrm{K}-\mathrm{a} \mathrm{K}+$ levemente amarillo pálido, $\mathrm{C}-, \mathrm{KC}+$ amarillo pálido, $\mathrm{P}-$. Superficie inferior ondulada, de color blanco-crema. Tomento ventral principal denso hasta el margen, grueso (largo), esponjoso, suave, de color crema. Tomento ventral secundario aracnoide, claro. Rizinas ausentes. Cifelas abundantes, $1-20$ por $\mathrm{cm}^{2}$ hacia el centro del talo y $1-20$ por $\mathrm{cm}^{2}$ hacia el margen, dispersas, irregulares, urceoladas con poro ancho, inmersas a erumpentes, abajo del nivel del tomento, con el margen revoluto de color blanco crema, con tomento; poro de $0,5-$ 3,0 mm de diámetro hacia el centro del talo; membrana basal pubescente, de color blanco, $\mathrm{K}-\mathrm{a} \mathrm{K}+$ amarillo pálido, $\mathrm{C}-$, $\mathrm{KC}+$ amarillo pálido, $\mathrm{P}-$. Picnidios no observados.

Corteza superior paraplectenquimática, de $25-40 \mu \mathrm{m}$ de grosor, homogénea, conformada por 3-5 capas de células, de 3-10 $\mu \mathrm{m}$ de diámetro, con la pared de $0,6-2,5 \mu \mathrm{m}$ de grosor y el lumen redondeado a isodiamétrico de 2,5-7 $\mu \mathrm{m}$ de diámetro. Capa de algas de 20-40 $\mu \mathrm{m}$ de grosor, con las células de 10-13 $\mu \mathrm{m}$ de diámetro. Médula de 40-75 $\mu \mathrm{m}$ de grosor, con hifas de 2,5 $\mu \mathrm{m}$ de ancho, sin cristales. Corteza inferior paraplectenquimática, de 20-25 $\mu \mathrm{m}$ de grosor, con 2-3 capas de células; células de 3-7,5 $\mu \mathrm{m}$ de diámetro, con la pared de $1,2-2,5 \mu \mathrm{m}$ de grosor. Tomento dorsal principal de 60-420 $\mu \mathrm{m}$ de largo, en fascículos de 12-20 hifas, hifas ramificadas, apicalmente moniliformes con los ápices libres. Tomento dorsal secundario de 15-25 $\mu \mathrm{m}$ de largo, solitario, hifas ramificadas, moniliformes con los ápices libres. Tomento ventral principal de $85-430 \mu \mathrm{m}$ de largo, en fascículos de 12-20 hifas, hifas ramificadas, apicalmente moniliformes con los ápices libres. Tomento ventral secundario de 15-25 $\mu \mathrm{m}$ de largo, solitario, hifas ramificadas, moniliformes con los ápices libres. Cavidad de las cifelas de 70-230 $\mu \mathrm{m}$ de alto; cifeloblastos con una papila.

E timología. Esta especie recibe su nombre por su semejanza con Sticta aff. fuliginosa, de la que se diferencia por la superficie hirsuto-tomentosa, márgenes de los lóbulos irregulares y cifelas sin papilas.

Distribución y ecología. Andes de Colombia. Se ha encontrado entre $2.550-4.000 \mathrm{~m}$, en bosques andinos $\mathrm{y}$ páramo, en lugares con intensidad lumínica baja, media y alta. Existen registros de las cordilleras Central y Oriental en las zonas de vida andina y de páramo de la región andina colombiana. Crece sobre corteza y roca, generalmente asociado con especies de los géneros Frullania, Metzgeria, Lejeunea y Plagiochila.

Discusión. Sticta hirsutofuliginosa es una especie con fotobionte cianobacterial, isidios laminares y tomento en la superficie dorsal. Tiene una cierta semejanza morfológica y en ocasiones de hábitat con S. arachnofuliginosa Moncada \& Lücking (Moncada \& Lücking, 2012b), la cual se diferencia por los talos planos a revolutos, fuertemente faveolados y el tomento dorsal pubescente homogéneo que cubre la totalidad del talo, además de los isidios cortos (hasta de $0,2 \mathrm{~mm}$ de altura), rara vez ramificados, y las cifelas planas. Sticta hirsutofuliginosa se asemeja tambien a $S$. humboldtii Hook. y sus relativos (M oncada, et al., 2013d), las cuales carecen de isidios y forman apotecios.

Especímenes examinados. COLOMBIA. Boyacá: Municipio de El Cocuy, Parque Nacional Natural El Cocuy, sendero de Cabaña Sisuma rumbo a Pico Pan de Azúcar; 3.800 4.800 m; 20 de abril, 2011, D. Fonseca \& F. Martínez 102 (UDBC). Alto de la Cueva; 3.800 m; 21 de abril, 2011, $D$. Fonseca \& F. Martínez 184, 231 (UDBC). Municipio de Villa de Leyva, SFF Iguaque, Caseta de administración a Villa de Leyva; 2.800 m; 29 de octubre, 2002, B. Moncada \& R. Dávila 1725 (UDBC). Cundinamarca: Municipio de Bogotá, D.C., sureste del cerro de Monserrate, oriente de Bogotá; 3.150 m; 27 de junio, 1971, M. Nee \& S. Mori 4235 (COL). Municipio de Bogotá, D.C., Parque Nacional Natural Sumapaz, alrededores de Laguna de Chisacá; $4^{\circ}$ 17’ 
N, 74 $12^{\prime}$ O; 3.730 m; 8 de abril, 2008, B. Moncada \& A. López 2646 (UDBC); ibid.; 3.724 m; 15 de agosto, 2010, B. Moncada, et al. 4032, 4147, 4998 (UDBC). Municipio de Choachí, El Verjón, Parque Ecológico Matarredonda; 4 34' N, 7400’ O; 3.220 m; 1 de octubre, 2007, D. Hernández, et al. 28 (UDBC); ibid.; 2.900-3.220 m; 8 de mayo, 2010, B. Moncada 3206 (UDBC); ibid.; $3.220 \mathrm{~m} ; 23$ de enero, 2011, B. Moncada 4606 (UDBC). Municipio de Guasca, Parque Nacional Natural Chingaza, Piedras Gordas; 3.200 m; 15 de octubre, 1988, H. Sipman \& J. Aguirre 27382a (B, COL). Páramo de Guasca; 3.350 m; 18 de agosto, 2011, B. Moncada 4730a, 4731, 4734b, 4737 (UDBC); ibid.; 3.200 m; 18 de agosto, 2011, R. Lücking 33309, 34050 (F, UDBC). Municipio de La Calera, Parque Nacional Natural Chingaza, Monterredondo; 4' 44' N, 73 ${ }^{\circ}$ 51' O; 3.430 m; 13 de abril, 2011, B. Moncada 4623, 4643b (UDBC). Laguna de Siecha; $4^{\circ} 44^{\prime}$ N, 73 51' O; 3.456 m; 8 de mayo, 2011, Y. Orozco \& R. Soto 80 (UDBC). Zona de amortiguación del Parque Nacional Natural Chingaza, Vía del ángulo al Rincón del Oso; 3.600 m; 7 de noviembre, 2011, B. Moncada 4923, 4929, 4941b, 4947, 4951 (UDBC). Nariño: Municipio de Pasto, a $10 \mathrm{~km} \mathrm{~N}$ de Pasto a lo largo de la carretera a Popayán; 2.550 m; 17 de junio, 1986, H. Sipman, R. Velosa, et al. 33617 (B, COL). Norte de Santander: Municipio de Toledo, Parque Nacional Natural Tamá, sector El Paramito; 2.800 m; 12 de septiembre, 2000, B. Moncada \& R. Dávila 1297, 1330 (UDBC). Tolima: Municipio de Líbano, Valle de Quebrada Blanca, afluente del río Lagunillas; $3.550 \mathrm{~m}$; 26 de agosto, 1985, H. Sánchez \& J. Hernández 904 (COL).

\section{Sticta jaguirreana M oncada \& L ücking sp. nov.}

\section{Index Fungorum IF550808}

Differing from Sticta phyllidiofuliginosa in the larger cyphellae and secondary tomentum.

Tipo. COLOMBIA. Cundinamarca: Municipio de Chipaque, vereda Marilandia, vía Santuario; 2.400 m; 8 de septiembre, 2011, B. Moncada 4804 (UDBC, holotipo; COL, isotipo). (Figura 5)

Descripción. Fotobionte primario cianobacteria. Pedúnculo ausente. Talo orbicular a irregular, hasta $10 \mathrm{~cm}$ de diámetro, medianamente ramificado, con 3-5 ramificaciones por $5 \mathrm{~cm}$ de radio, ramificación politómica. Lóbulos suborbiculares a flabelados, horizontales, imbricados, planos a involutos, con los ápices redondeados, involutos, márgenes enteros a crenados, no engrosados; entrenudos de los lóbulos de (4-)5-12(-20) mm de largo, (2-)5-15(-20) $\mathrm{mm}$ de ancho, papiráceos, frágiles. Superficie superior lisa a levemente escrobiculada, de color verde azulado cuando fresco, gris amarilla verdosa en el herbario, poco brillante, con la línea marginal marrón; superficie glabra a escabrosa, sin papilas, sin pruina, con máculas irregulares diminutas, amarillas. Cilios escasos, simples, beis a marrón dorado, hasta de 0,2 mm de largo. Apotecios no observados. Propágulos vegetativos presentes, abundantes, en forma de filidios, principalmente

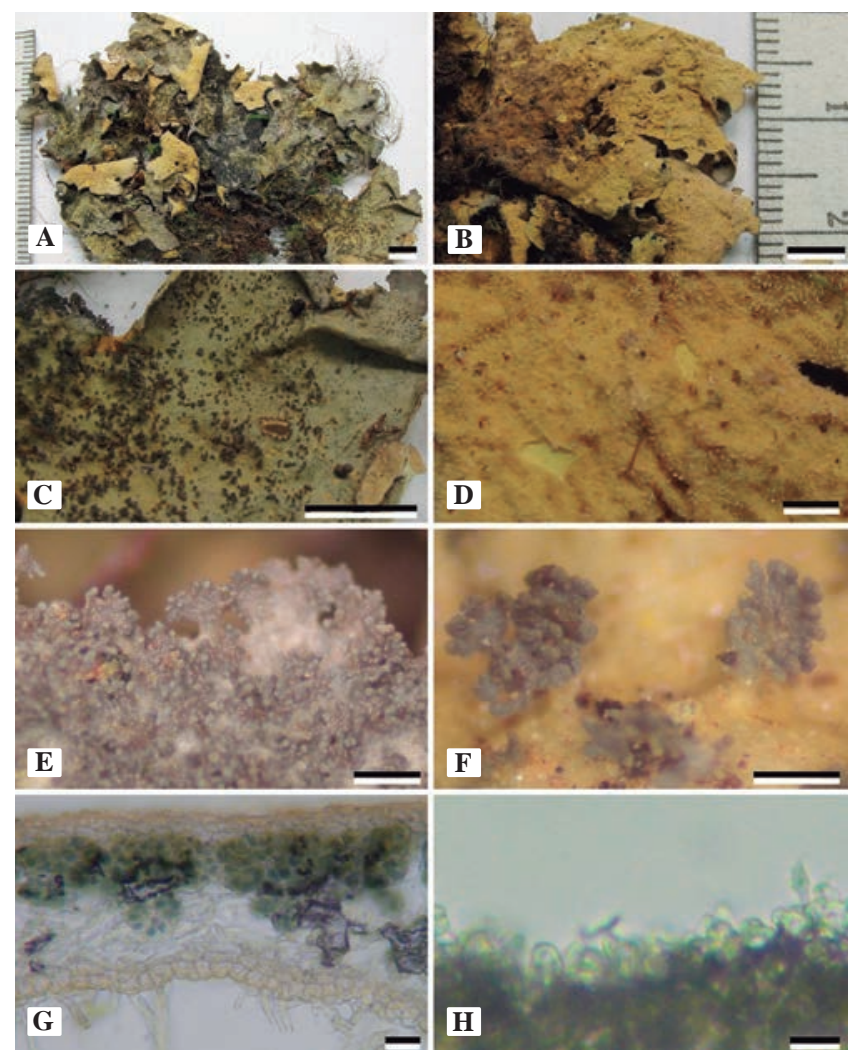

Figura 5. Sticta jaguirreana. A. Vista dorsal del talo. B. Vista ventral del talo. C. Detalle de la superficie dorsal. D. Detalle del tomento ventral y de las cifelas. E-F. Detalle de los filidios laminares. G. Anatomía del talo. H. Cifeloblastos con papilas. A-C $=5 \mathrm{~mm}, \mathrm{D}-\mathrm{F}=1 \mathrm{~mm}, \mathrm{G}-\mathrm{H}=20 \mu \mathrm{m}$

laminares, dispersos a subagregados, ramificados, palmeados, oblicuos a levemente verticales, hasta de $1 \mathrm{~mm}$ de largo y 1,5 $\mathrm{mm}$ de ancho, con ramificaciones cilíndricas apicales, radiales, diminutas, de menos de 0,02 mm de ancho, más oscuros que el talo, de color azul grisáceo, opacos, en sección transversal dorsiventrales, escuamiformes; pedúnculo si presente, cilíndrico a levemente aplanado, sin cifelas. Médula laxa, de color amarillo, $\mathrm{K}-, \mathrm{C}-, \mathrm{KC}-, \mathrm{P}-$. Superficie inferior faveolada, de color amarillo. Tomento ventral principal denso hasta el margen, delgado (corto), fasciculado a fasciculado-esponjoso, suave, de color crema. Tomento ventral secundario ausente. Rizinas ausentes. Cifelas escasas, $1-10$ por $\mathrm{cm}^{2}$ hacia el centro del talo y $21-$ 40 por $\mathrm{cm}^{2}$ hacia el margen, agregadas, irregulares, planas a cupuliformes, prominentes a sésiles, abajo del nivel del tomento, con el margen indiferenciado de color amarillo, sin tomento $\mathrm{u}$ ocasionalmente con tomento; poro de $(0,4-) 0,5$ $0,8(-1) \mathrm{mm}$ de diámetro hacia el centro del talo; membrana basal pubescente, de color amarillo, $\mathrm{K}-, \mathrm{C}-, \mathrm{KC}-, \mathrm{P}-$. Picnidios no observados.

Corteza superior paraplectenquimática, de 12-20 $\mu \mathrm{m}$ de grosor, homogénea, conformada por 2-3 capas de células, de 4-12 $\mu \mathrm{m}$ de diámetro, con la pared de 0,6-1,2 $\mu \mathrm{m}$ de 
grosor y el lumen redondeado a isodiamétrico de 2,5-10 $\mu \mathrm{m}$ de diámetro. Capa de algas de 35-60 $\mu \mathrm{m}$ de grosor, con las células de 10-18 $\mu \mathrm{m}$ de diámetro. Médula de 40-185 $\mu \mathrm{m}$ de grosor, con hifas de 2,5 $\mu \mathrm{m}$ de ancho, sin cristales. Corteza inferior paraplectenquimática, de 15-18 $\mu \mathrm{m}$ de grosor, con 1-2 capas de células; células de 4-15 $\mu \mathrm{m}$ de diámetro, con la pared de 1,2-2,5 $\mu \mathrm{m}$ de grosor. Tomento ventral principal de $8-115 \mu \mathrm{m}$ de largo, solitario, hifas simples, septadas con los ápices libres. Cavidad de las cifelas 70-200 $\mu \mathrm{m}$ de alto; cifeloblastos con una papila.

E timología. Esta especie recibe su nombre en honor del Dr. Jaime Aguirre Ceballos, por sus aportes a la liquenología colombiana.

Distribución y ecología. Andes de Colombia. Se ha encontrado entre 2.400 y $3.000 \mathrm{~m}$, en lugares abiertos y cerrados con diferentes exposiciones solares, en la zona de vida andina de la región andina colombiana, en las cordilleras Central y Occidental, creciendo sobre corteza musgosa, troncos caídos y, más raramente, sobre suelo, generalmente asociada con Lophocolea, Plagiochila, Campylopus y Leptogium.

Discusión. Sticta jaguirreana es probablemente el cianomorfo de una especie fotosimbiodémica, ya que presenta las características típicas de los cianomorfos de fotosimbiodemas que se han encontrado en Colombia (Moncada, et al., 2013c). Podría llegar a confundirse con S. phyllidiofuliginosa (ver abajo), de la que se separa por la presencia de tomento secundario y las cifelas grandes con el margen involuto a recto. También puede confundirse con los cianomorfos de S. phyllidiokunthii Moncada \& Lücking (Moncada, et al., 2013c), de la cual se diferencia por la superficie lisa a foveolada (punteado-impresa), y del cianomorfo de S. neopulmonarioides Moncada \& Coca (M oncada, et al., 2013e) por el largo pedúnculo y las filidios mayormente marginales.

Especímenes examinados. COLOMBIA. Boyacá: Municipio de Gachantivá, Laguna Las Coloradas; 2.450 m; 7 de julio, 1999, B. Moncada \& R. Dávila 445 (UDBC). Cundinamarca: Municipio de Chipaque, vereda Marilandia, vía Santuario; 2.400 m; 8 de septiembre, 2011, B. Moncada 4804 (UDBC). Municipio de Fómeque, Parque Nacional Natural Chingaza, embalse de Chuza; 3.000 m; 15 de octubre, 1988, H. Sipman \& J. Aguirre 27417 (B, COL). Municipio de San Francisco, vereda Sabaneta; 2.500 m; 17 de julio, 1986, H. Sipman, et al. 23603 (B, COL). Quindío: Municipio de Salento, vereda Río Arriba, Finca La Montaña, orillas del río Quindío; 2.800 m; 8 de mayo, 1990, J. Uribe, et al. 1073, 1115 (COL).

\section{Sticta macrofuliginosa M oncada \& L ücking sp. nov.}

\section{Index Fungorum IF550809}

Differing from Sticta aff. fuliginosa by the larger, scrobiculate-faveolate, usually apotheciate thalli.

Tipo. COLOMBIA. Cundinamarca: Municipio de Bogotá, D.C., Parque Nacional Natural Sumapaz, alrededores de la Laguna de Chisacá; $4^{\circ} 17^{\prime}$ N, 74 12' O; 3.724 m; 15 de agosto, 2010, B. Moncada, et al. 4042 (UDBC, holotipo; COL, F, FAUC, isotipos). (Figura 6)

Descripción. Fotobionte primario cianobacteria. Pedúnculo ausente. Talo orbicular a irregular, hasta de $15 \mathrm{~cm}$ de diámetro, medianamente ramificado, con 3-5 ramificaciones por $5 \mathrm{~cm}$ de radio, ramificación politómica. Lóbulos suborbiculares, horizontales a subpéndulos, imbricados, ondulados a levemente revolutos, con los ápices redondeados a irregulares, revolutos, márgenes enteros a crenados, no engrosados; entrenudos de los lóbulos de 10-20 mm de largo, (8-)15-25(-50) $\mathrm{mm}$ de ancho, papiráceos a subcoriáceos, resistentes, maleables. Superficie superior escrobiculada a faveolada, de color verde marrón cuando fresco, marrón claro hacia el centro y marrón oscuro hacia el margen en el herbario, brillante, con la línea marginal del mismo color; superficie glabra, sin papilas, sin pruina, con máculas irregulares, cremas. Cilios ausentes. Apotecios escasos, principalmente laminares, dispersos, subpedicelados, invaginación basal inferior pronunciada, hasta de $2,5 \mathrm{~mm}$ de diámetro; disco de color marrón rojizo, brillante; margen entero a tomentoso pubescente hacia la base del apotecio,
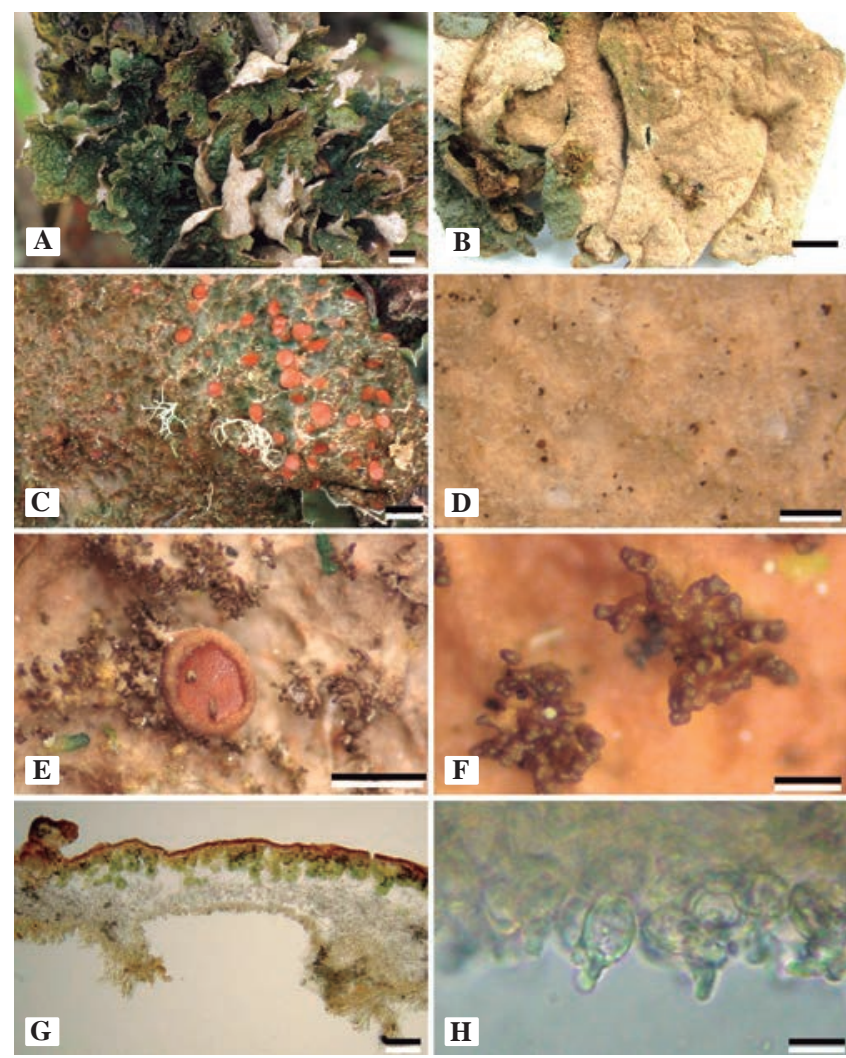

Figura 6. Sticta macrofuliginosa. A. Vista dorsal del talo en vivo. B. Vista ventral del talo en seco. C. Detalle de la superficie dorsal que muestra isidios y apotecios laminares. D. Detalle del tomento ventral y de las cifelas. E. Detalle de los isidios laminares y apotecio. F. Detalle de los isidios. G. Detalle de la cifela. H. Cifeloblastos con una papila. Escala: A-B $=1 \mathrm{~cm}, \mathrm{C}=5 \mathrm{~mm}$, D-E $=2,5 \mathrm{~mm}, \mathrm{~F}=2 \mathrm{~mm}, \mathrm{G}=100 \mu \mathrm{m}, \mathrm{H}=10 \mu \mathrm{m}$ 
de color crema cuando joven y marrón cuando maduro. Propágulos vegetativos presentes, abundantes, en forma de isidios y lóbulillos (formados de los isidios que se desarrollan en el talo), principalmente laminares (los isidios), mayormente en las costillas de los escrobiculos, mientras que los lobulillos cuando presentes, aparecen marginales, agregados, simples a ramificados, los isidios coraloides, los lóbulillos palmeados, los isidios verticales, los lóbulillos horizontales, los isidios hasta de 0,5 mm de largo, los lóbulos hasta de $1 \mathrm{~mm}$ de largo y los isidios de $0,3 \mathrm{~mm}$ de ancho, los lóbulillos de 1,5 mm de ancho, más oscuros que el talo, opacos a poco brillantes, en sección transversal los isidios redondos, los lobulillos dorsiventrales, isidios cilíndricos y lobulillos lobuliformes; pedúnculo si presente, cilíndrico, sin cifelas. Médula laxa, de color blanco, $\mathrm{K}-\mathrm{a}$ $\mathrm{K}+$ levemente amarillo pálido, $\mathrm{C}-, \mathrm{KC}+$ amarillo pálido, $\mathrm{P}-$. Superficie inferior ondulada a rugosa, de color crema. Tomento ventral principal denso hasta el margen, grueso (hasta de 0,5 mm de largo), esponjoso, suave, de color crema a beis. Tomento ventral secundario aracnoide, claro. Rizinas escasas, irregularmente dispersas, escurarrosas a anziformes, de color crema, hasta de 1,5 mm de largo. Cifelas escasas, $1-20$ por $\mathrm{cm}^{2}$ hacia el centro del talo y $21-40$ por $\mathrm{cm}^{2}$ hacia el margen, dispersas, redondeadas a irregulares, urceoladas con poro ancho a cupuliformes cuando muy abiertas, inmersas a erumpentes, abajo del nivel del tomento, con el margen involuto a recto de color crema, con tomento; poro de $(0,2-) 0,5-0.7(-1) \mathrm{mm}$ de diámetro hacia el centro del talo; membrana basal pubescente, de color blanco, $\mathrm{K}+$ amarillo, $\mathrm{C}-, \mathrm{KC}-$, $\mathrm{P}-$. Picnidios no observados.

Corteza superior paraplectenquimática, de 20-25 $\mu \mathrm{m}$ de grosor, homogénea, conformada por 2-3 capas de células, de 4-11 $\mu \mathrm{m}$ de diámetro, con la pared de 0,6-1,2 $\mu \mathrm{m}$ de grosor y el lumen redondeado a isodiamétrico de 2,5-10 $\mu \mathrm{m}$ de diámetro. Capa de algas de 35-50 $\mu \mathrm{m}$ de grosor, con las células de 10-20 $\mu \mathrm{m}$ de diámetro. Médula de 70-135 $\mu \mathrm{m}$ de grosor, con hifas de $2,5 \mu \mathrm{m}$ de ancho, sin cristales. Corteza inferior paraplectenquimática, de 20-25 $\mu \mathrm{m}$ de grosor, con 2-4 capas de células; células de 4-12 $\mu \mathrm{m}$ de diámetro, con la pared de $1-1,2 \mu \mathrm{m}$ de grosor. Tomento dorsal ausente. Tomento ventral principal de 70-240 $\mu \mathrm{m}$ de largo, en fascículos de 12-20 hifas, hifas ramificadas, apicalmente moniliformes con los ápices libres. Tomento ventral secundario de 12-35 $\mu \mathrm{m}$ de largo, solitario, hifas ramificadas, moniliformes con los ápices libres. Cavidad de las cifelas $40-100 \mu \mathrm{m}$ de alto; cifeloblastos con una papila. Apotecios biatorinos, hasta de $280 \mu \mathrm{m}$ de alto, sin pedúnculo; excípulo de 85-90 $\mu \mathrm{m}$ de ancho, con tomento. Himenio hasta de $85 \mu \mathrm{m}$ de alto; epihimenio hasta de 2,5 $\mu \mathrm{m}$ de alto, de color naranja, sin capa gelatinosa. Ascosporas de $18-30$ ' 7-8 $\mu \mathrm{m}$, fusiformes, con 1-3 septos.

E timología. Esta especie recibe su nombre por su semejanza con Sticta aff. fuliginosa, de la que se diferencia por su gran tamaño y apotecios frecuentemente presentes.
Distribución y ecología. Andes de Colombia. Se ha encontrado entre 3.000-4.400 m, en bosques andinos y de páramo, en lugares con intensidad lumínica media a alta. Se cuenta con registros de su presencia en la vertiente occidental de la cordillera Central y las vertientes oriental y occidental de la cordillera Occidental en las zonas de vida andina a páramo de la región andina colombiana. Crece sobre corteza, generalmente asociada con especies de las hepáticas Metzgeria y Frullania y el líquen Heterodermia vulgaris.

Discusión. Sticta macrofuliginosa es una especie con morfotipo semejante a S. fuliginosa (M oncada \& L ücking, 2012b), con la cual comparte los talos suborbiculares y las isidios laminares; sin embargo, los talos pequeños con papilas y con isidios frágiles de $S$. fuliginosa hacen fácil su reconocimiento. Sticta gallowayana (ver arriba) es otra especie con la que se puede confundir $S$. macrofuliginosa, pero los isidios corimbosos, los talos sin filidios o lobulillos y la ausencia de apotecios son importantes para la diferenciación de esta.

Especímenes examinados. COLOMBIA. Boyacá: Municipio de El Cocuy, Parque Nacional Natural El Cocuy, Valle de Las Lagunillas, Cabaña Sisuma; 6 26’ N, 72² 22’ O; 3.800 m; 19 de abril, 2011, D. Fonseca \& F. Martínez 31a, 47 (UDBC). Alto de la Cueva; 3.800 m; 21 de abril, 2011, $D$. Fonseca \& F. Martínez 198, 235 (UDBC). Caldas: Municipio de Villa María, Nevado del Ruíz, costado noroccidental, cerca al Refugio; 3.500 m; 3 de febrero, 1979, H. Sipman \& H. Valencia 10439 (COL,U). Cauca: Municipio de Puracé, costado oriental, cordillera Central. Carretera La Plata a Puracé, $2 \mathrm{~km}$ de las termales de San Juan; 3.000 m; 4 de octubre, 1984, J. Aguirre \& H. Sipman 5922 (B, COL). Cundinamarca: Municipio de Bogotá, D.C., Parque Nacional Natural Sumapaz; 3.600 m; 8 de marzo, 1980, S. Salamanca, et al. 934 (COL); ibid.; Laguna de Chisacá; 3.660 m; 23 de marzo, 1982, J. Aguirre 2713 (COL). Parque Nacional Natural Sumapaz, Páramo de Chisacá, carretera Usme, Nazareth, hacia la Laguna Grande.; 3.700 m; 4 de septiembre, 1984, J. Aguirre \& H. Sipman 5004b (COL). Páramo de Chisacá, carretera a la Laguna Larga; 3.500 m; 15 de julio, 1986, N. Cardona de Hollaender, et al. 40 (CUVC). Parque Nacional Natural Sumapaz, alrededores de la Laguna de Chisacá; $4^{\circ}$ 17’ N, 74 12' O; 3.734 m; 8 de abril, 2008, D. Beltrán, et al. 25 (UDBC); ibid.; 3.724 m; 15 de agosto, 2010, B. Moncada, et al. 4042, 4134a, 4137, 4138, 4146 (UDBC); ibid.; 3.600 m; 10 de diciembre, 2010, B. Moncada 5101, 5102, 5107, 5150 (UDBC). Municipio de La Calera, Parque Nacional Natural Chingaza, Monterredondo; $4^{\circ}$ 44' N, 73 51' O, 3.430 m; 13 de abril, 2011, B. Moncada 4625, 4636b (UDBC). Zona de amortiguación del Parque Nacional Natural Chingaza, Vía del ángulo al Rincón del Oso; 3.600 m; 7 de noviembre, 2011, B. Moncada 4942, $4972 b$ (UDBC). Norte de Santander: Municipio de Chitagá, Páramo del Almorzadero; 3.400 m; 12 de mayo, 1979, J. Luteyn \& M. Lebrón 7656 (COL). Tolima: Municipio de 
Santa Isabel, Valle del Río Totarito, entre el Paso Español y Hacienda La Ermita; 3.650 m; 9 de febrero, 1980, $H$. Valencia \& T. Boekhout 131a (COL).

\section{Sticta minutula M oncada \& L ücking sp. nov.}

Index Fungorum IF550810

Differing from Sticta hirsutofuliginosa in the smaller thalli with minutely pubescent surface.

Tipo. COLOMBIA. Cundinamarca: Municipio de Guasca, Páramo de Guasca; 3.350 m; 18 de agosto 2011, B. Moncada 4753 (UDBD, holotipo; CUCV, F, isotipos). (Figura 7)

Descripción. Fotobionte primario cianobacteria. Pedúnculo ausente. Talo orbicular, hasta de $5 \mathrm{~cm}$ de diámetro, poco ramificado, con 0-2 ramificaciones por $5 \mathrm{~cm}$ de radio, ramificación politómica. Lóbulos suborbiculares, horizontales a levemente subpéndulos, imbricados, revolutos, con los ápices redondeados, revolutos, márgenes enteros a crenados; entrenudos de los lóbulos de 18-30 mm de largo, (8-)12$30(-40) \mathrm{mm}$ de ancho, coriáceos, frágiles. Superficie superior escrobiculada a faveolada, de color verde oscuro cuando fresco, marrón negruzco en el herbario, poco brillante, con

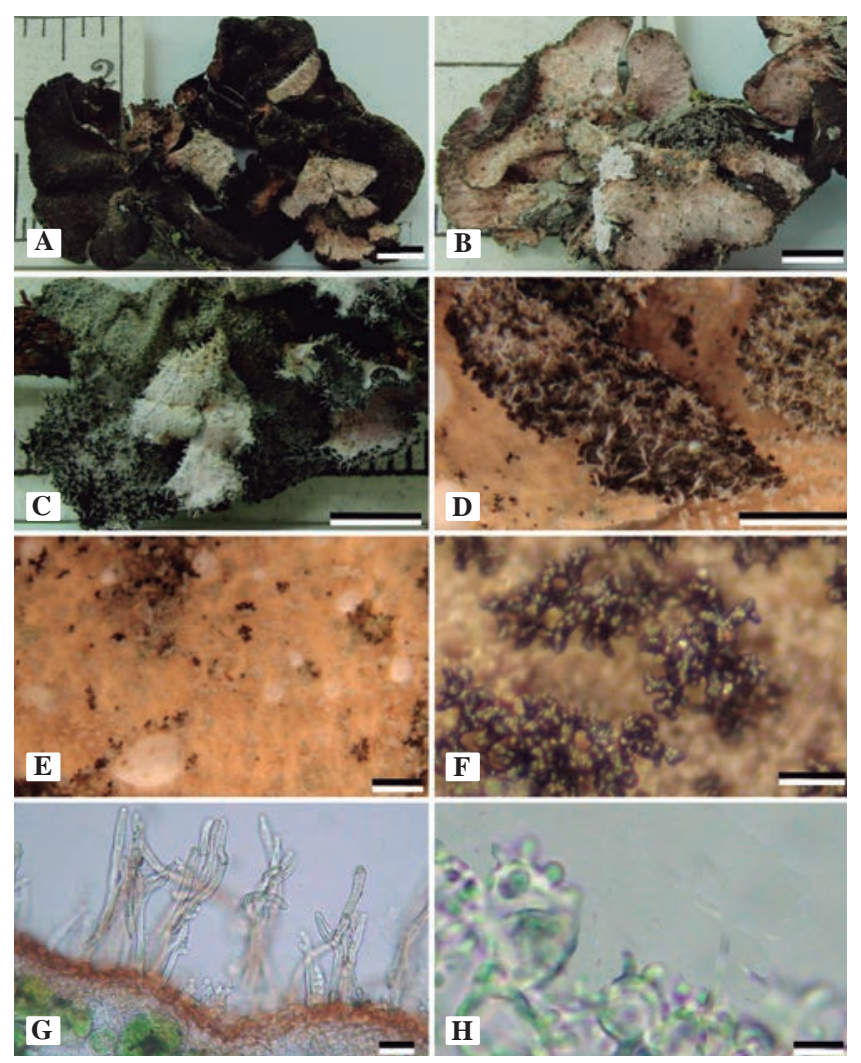

Figura 7. Sticta minutula. A. Vista dorsal del talo. B. Vista ventral del talo. C. Detalle de la superficie ventral. D. Detalle del tomento dorsal. E. Detalle del tomento ventral y de las cifelas. F. Detalle de los isidios laminares. G. Detalle del tomento dorsal. H. Cifeloblastos con papilas. Escala: $\mathrm{A}=1 \mathrm{~cm}, \mathrm{~B}-\mathrm{D}=5 \mathrm{~mm}, \mathrm{E}=1$ $\mathrm{mm}, \mathrm{F}=0,1 \mathrm{~mm}, \mathrm{G}=10 \mu \mathrm{m}, \mathrm{H}=5 \mu \mathrm{m}$ la línea marginal del mismo color; superficie pubescente a hirsuta, sin papilas, sin pruina, con máculas irregulares, casi imperceptibles, cremas. Cilios ausentes. Apotecios no observados. Isidios abundantes, principalmente laminares, sobre las costillas o en el borde de las escrobiculas o invaginaciones del talo, agregados, ramificados, coraloides, verticales, hasta de 0,2 $\mathrm{mm}$ de largo y 0,05 $\mathrm{mm}$ de ancho, más oscuros que el talo, de color marrón negruzco, brillantes, en sección transversal redondos, granulares a cilíndricos; pedúnculo si presente, cilíndrico, sin cifelas. Médula laxa, de color blanco, K-, C-, KC-, P-. Superficie inferior ondulada a faveolada en las zonas más viejas, de color crema. Tomento ventral principal escaso en toda la superficie, grueso (largo), esponjoso, suave, de color blanco crema. Tomento ventral secundario aracnoide, claro. Rizinas ausentes. Cifelas escasas, $1-10$ por $\mathrm{cm}^{2}$ hacia el centro del talo y $21-40$ por $\mathrm{cm}^{2}$ hacia el margen, dispersas, irregulares, cupuliformes a levemente urceoladas con poro ancho, inmersas, abajo del nivel del tomento, con el margen indiferenciado a levemente involuto de color blanco crema, con tomento; poro de $0,3-$ 1,5 mm de diámetro hacia el centro del talo; membrana basal pubescente, de color blanco, $\mathrm{K}+$ amarillo pálido a amarillo, $\mathrm{C}-, \mathrm{KC}+$ amarillo pálido, $\mathrm{P}-$. Picnidios no observados.

Corteza superior paraplectenquimática, de 30-40 $\mu \mathrm{m}$ de grosor, homogénea, conformada por 3-5 capas de células, de 4-10 $\mu \mathrm{m}$ de diámetro, con la pared de 1,2-2,5 $\mu \mathrm{m}$ de grosor y el lumen redondeado a isodiamétrico de 2,5-7,5 $\mu \mathrm{m}$ de diámetro. Capa de algas de 30-70 $\mu \mathrm{m}$ de grosor, con las células de 12-20 $\mu \mathrm{m}$ de diámetro. Médula de 120-200 $\mu \mathrm{m}$ de grosor, con hifas de 2,5 $\mu \mathrm{m}$ de ancho, sin cristales. Corteza inferior paraplectenquimática, de 20-35 $\mu \mathrm{m}$ de grosor, con 2-3 capas de células; células de 4-10 $\mu \mathrm{m}$ de diámetro, con la pared de 1,2-2,5 $\mu \mathrm{m}$ de grosor. Tomento dorsal principal de 25-50 $\mu \mathrm{m}$ de largo, en fascículos de 6 hifas, hifas simples, septadas con los ápices libres. Tomento dorsal secundario de 10-25 $\mu \mathrm{m}$ de largo, solitario, hifas ramificadas, moniliformes con los ápices libres. Tomento ventral principal de 80-3200 $\mu \mathrm{m}$ de largo, en fascículos de 12-20 hifas, hifas ramificadas, apicalmente moniliformes con los ápices libres. Tomento ventral secundario de 15-35 $\mu \mathrm{m}$ de largo, solitario, hifas ramificadas, moniliformes con los ápices libres. Cavidad de las cifelas de 200-1100 $\mu \mathrm{m}$ de alto; cifeloblastos con numerosas papilas.

E timología. Esta especie recibe este nombre por su tamaño generalmente pequeño.

Distribución y ecología. Andes de Colombia. Se ha encontrado desde 1.750 a $3.500 \mathrm{~m}$, en las zonas de vida subandina a páramo de la región andina colombiana, en las cordilleras Oriental y Occidental. Crece sobre corteza y generalmente está asociado con Frullania y Plagiochila.

Discusión. Sticta minutula forma parte del grupo morfológicamente semejante a $S$. aff. fuliginosa, en el que se incluye también por la presencia de papilas en los cifeloblastos 
(Moncada \& Lücking, 2012b). Se podría confundir con S. hirsutofuliginosa (ver arriba), S. arachnofuliginosa (M oncada \& L ücking, 2012b) y S. ciliata. De la primera se diferencia por la superficie dorsal débilmente pubescente, en ocasiones glabra en zonas cercanas al margen y con abundantes setas esponjosas hacia el centro del talo. De $S$. arachnofuliginosa se distingue por el tomento pubescente homogéneo y cifelas planas y de $S$. ciliata, por el talo frágil con la superficie pubescente aracnoidea y diminutas papilas.

E specímenes examinados. COLOMBIA. Cundinamarca: Municipio de Guasca, Páramo de Guasca; 3.350 m; 18 de agosto, 2011, B. Moncada 4729, 4732, 4738, 4753, 4755 (UDBC). Municipio de La Calera, Páramo de Palacio, Hacienda La Siberia; 3.500 m; 5 de enero, 1960, L. E. Mora 906a (COL). Parque Nacional Natural Chingaza, Monterredondo; 4 ${ }^{\circ} 44^{\prime}$ N, 73 ${ }^{\circ}$ 51' O; 3.430 m; 13 de abril, 2011, B. Moncada 4639 (UDBC). Nariño: Municipio de Piedrancha, La Planada, San Isidro, sur de Ricaurte (carretera Pasto a Tumaco); 1.750 m; 2 de junio, 1986, H. Sipman, $R$. Velosa, et al. 32845 (B, COL). Norte de Santander: Municipio de Toledo, Parque Nacional Natural Tamá, sector Orocué, alrededores de la caseta de administración; 2.690 m; 12 de septiembre, 2000, B. Moncada \& R. Dávila 1221 (UDBC).

\section{Sticta phyllidiofuliginosa M oncada \& L ücking sp. nov.}

Index Fungorum IF550811

Differing from Sticta aff. fuliginosa in the large, applanate to phyllidiate isidia.

Tipo. COLOMBIA. Cundinamarca: Municipio de Bogotá, D.C., alrededores de la Laguna de Chisacá; $4^{\circ} 17^{\prime} \mathrm{N}, 74^{\circ} 12^{\prime}$ O; 3.724 m; 15 de agosto, 2010, B. Moncada, et al. 4051 (UDBC, holotipo). (Figura 8)

Descripción. Fotobionte primario cianobacteria. Pedúnculo ausente. Talo orbicular a irregular, hasta de $10 \mathrm{~cm}$ de diámetro, poco ramificado, con $0-2$ ramificaciones por $5 \mathrm{~cm}$ de radio, ramificación politómica. Lóbulos suborbiculares, horizontales a subpéndulos, imbricados, ondulados, con los ápices redondeados a irregulares, involutos, márgenes enteros a crenados, no engrosados; entrenudos de los lóbulos de 10-20 mm de largo, (10-)12-15(-22) $\mathrm{mm}$ de ancho, subcoriáceos, resistentes. Superficie superior escrobiculada a faveolada, de color verde marrón cuando fresco, gris marrón en el herbario, opaca, con la línea marginal del mismo color; superficie glabra, sin papilas, sin pruina, con máculas irregulares, cremas. Cilios ausentes. Apotecios no observados. Propágulos vegetativos presentes, abundantes, en forma de filidios, principalmente laminares, dispersos a subagregados, simples a ramificados, espatulados a coraloides, verticales a levemente oblicuos, hasta de $1 \mathrm{~mm}$ de largo y 0,5 mm de ancho, de color igual al talo, opacos a poco brillantes, en sección transversal dorsiventrales, espatulados; pedúnculo si presente cilíndrico a levemente aplanado en isidios viejos, sin cifelas. Médula laxa, de

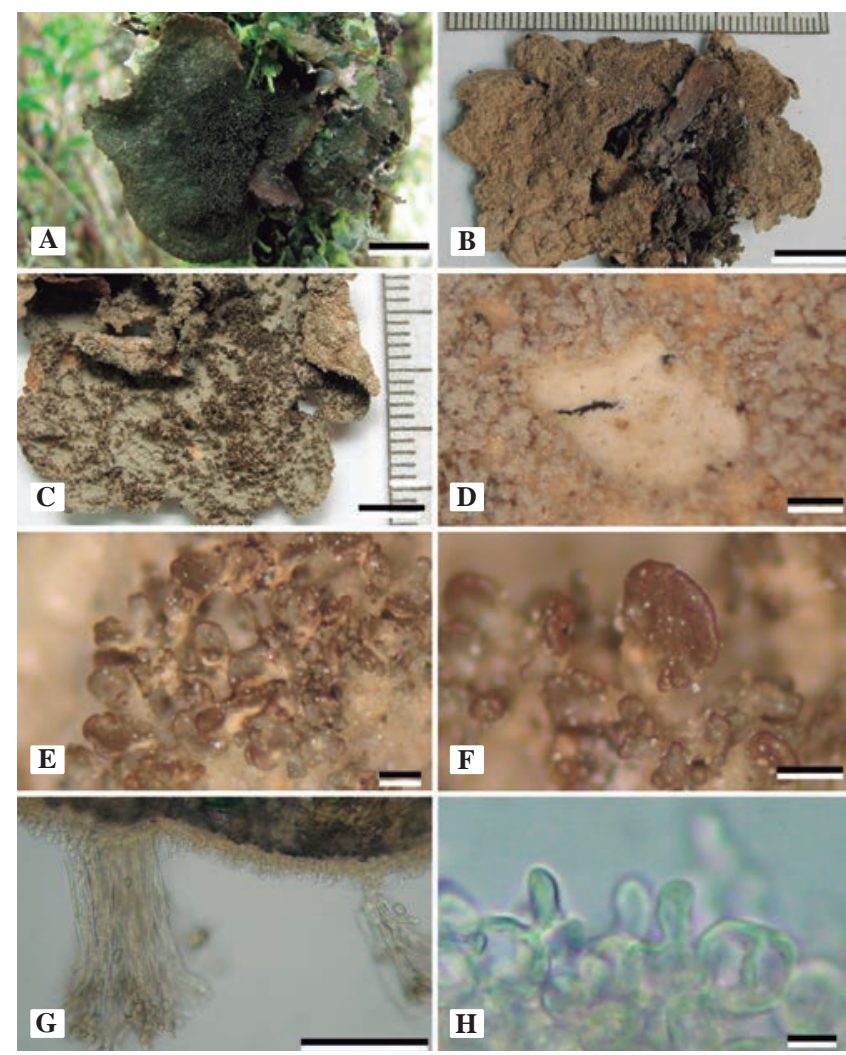

Figura 8. Sticta phyllidiofuliginosa. A. Vista dorsal del talo en vivo. B. Vista ventral del talo en seco. C. Detalle de la superficie dorsal que muestra filidios laminares. D. Detalle del tomento ventral y de la cifela. E-F. Detalle de los filidios. G. Detalle del tomento ventral primario y del secundario. $\mathrm{H}$. Cifeloblastos con una papila. Escala: $A-B=1 \mathrm{~cm}, \mathrm{C}-\mathrm{D}=5 \mathrm{~mm}, \mathrm{E}-\mathrm{F}=0,5 \mathrm{~mm}, \mathrm{G}=$ $100 \mu \mathrm{m}, \mathrm{H}=10 \mu \mathrm{m}$

color blanco, $\mathrm{K}-\mathrm{a} \mathrm{K}+$ levemente amarillo pálido, $\mathrm{C}-, \mathrm{KC}+$ amarillo pálido, $\mathrm{P}-$. Superficie inferior ondulada a rugosa, de color blanco amarillento. Tomento ventral principal denso hasta el margen, grueso, más delgado hacia el margen, esponjoso, suave, de color crema. Tomento ventral secundario pubescente, claro. Rizinas escasas, irregularmente dispersas, fasciculadas, de color crema a marrón, hasta de $1 \mathrm{~mm}$ de largo. Cifelas escasas, $1-20$ por $\mathrm{cm}^{2}$ hacia el centro del talo y $21-40$ por $\mathrm{cm}^{2}$ hacia el margen, dispersas, redondeadas a irregulares, urceoladas con poro ancho a cupuliformes cuando muy abiertas, inmersas a erumpentes, abajo del nivel del tomento, con el margen involuto a recto de color crema, sin tomento u ocasionalmente con tomento; poro de $(0,3-) 0,7-1(-2) \mathrm{mm}$ de diámetro hacia el centro del talo; membrana basal pubescente, de color blanco, $\mathrm{K}-, \mathrm{C}-$, $\mathrm{KC}-$, $\mathrm{P}-$. Picnidios no observados.

Corteza superior paraplectenquimática, de 15-30 $\mu \mathrm{m}$ de grosor, homogénea, conformada por 2-3 capas de células, de 4-10 $\mu \mathrm{m}$ de diámetro, con la pared de 1,2-2,5 $\mu \mathrm{m}$ de grosor y el lumen redondeado a isodiamétrico de 1,2-2,5 $\mu \mathrm{m}$ de diámetro. Capa de algas de 35-65 $\mu \mathrm{m}$ de grosor, con 
las células de 10-15 $\mu \mathrm{m}$ de diámetro. Médula de 75-200 $\mu \mathrm{m}$ de grosor, con hifas de 2,5 $\mu \mathrm{m}$ de ancho, sin cristales. Corteza inferior paraplectenquimática, de 12-18 $\mu \mathrm{m}$ de grosor, con 1-3 capas de células; células de 4-14 $\mu \mathrm{m}$ de diámetro, con la pared de $1,2-2,5 \mu \mathrm{m}$ de grosor. Tomento dorsal secundario de 5-20 $\mu \mathrm{m}$ de largo, solitario, hifas ramificadas, moniliformes con los ápices libres. Tomento ventral principal de 137-165 $\mu \mathrm{m}$ de largo, en fascículos de 12-20 hifas, hifas ramificadas, septadas con los ápices libres. Tomento ventral secundario de 3-12 $\mu \mathrm{m}$ de largo, solitario, hifas ramificadas, moniliformes con los ápices libres. Cavidad de las cifelas de 95-110 $\mu \mathrm{m}$ de alto; cifeloblastos con una papila.

Etimología. Esta especie debe su nombre a su semejanza con Sticta fuliginosa, de la cual se distingue por los amplios talos semicoriáceos y la formación de filidios.

Distribución y ecología. Andes de Colombia. Se ha encontrado entre 2.400-3.975 m, en bosques andinos y de páramo, en lugares con intensidad lumínica media a alta. Se cuenta con registros de su presencia en la vertiente occidental de las cordilleras Central y Oriental, en las zonas de vida andina a páramo de la región andina colombiana. Crece sobre corteza, hoja y suelo, generalmente asociada con especies de Radula y Plagiochila y algunas especies de la familia Lejeuneaceae, además de líquenes del género Leptogium.

Discusión. Esta especie pertenece al morfotipo de S. fuliginosa pero se distingue por formar isidios aplanados a filidios que en ocasiones se desarrollan como individuos nuevos sobre el talo. Su talo es bastante más grande que los de $S$. fuliginosa y se puede comparar con las especies $S$. arachnofuliginosa (M oncada \& L ücking, 2012b) cuya superficie dorsal es tomentosa y con isidios cilíndricos, simples a ramificados, y S. globulifuliginosa (ver arriba) por sus isidios globulares.

E specímenes examinados. COLOMBIA. Boyacá: Municipio de El Cocuy, Parque Nacional Natural El Cocuy, Valle de las Lagunillas, Cabaña Sisuma; 6 26' N, 72 ${ }^{\circ} 22^{\prime}$ O; 3.800 m; 19 de abril, 2011, D. Fonseca \& F. Martínez 86 (UDBC). Cundinamarca: Municipio de Bogotá, D.C., Páramo de Cruz Verde, carretera Bogotá-Choachí Km. 16; 3.390 m; 26 de mayo, 1972, A. M. Cleef \& T. Duncan 3171 (COL, U). Parque Nacional Natural Sumapaz, Páramo de Chisacá, Valle del Río Santa Rosa; 3.400 m; 4 de septiembre, 1984, J. Aguirre \& H. Sipman 5072 (B, COL). Alrededores de la Laguna de Chisacá; $4^{\circ} 17^{\prime}$ N, 74 12' O; 3.724 m; 15 de agosto, 2010, B. Moncada, et al. 4051, 4052, 4129 (UDBC). Municipio de Facatativá, Valle del Río Dulce, a 10 km NO de Facatativá; 2.600 m; 1 de febrero, 1979, H. Sipman, et al. 10350 (COL, U). Risaralda: Municipio de Pereira, Parque Nacional Natural Los Nevados, Laguna de Otún, margen occidental; 3.975 m; 16 de enero, 1980, T. Boekhout 19 (B, COL).

\section{Sticta plumbeociliata M oncada \& L ücking sp. nov.}

Index Fungorum IF550812

Differing from Sticta cometiella in the absence of a secondary lower tomentum and white cilia.
Tipo. COLOMBIA. Cundinamarca: Municipio de Chipaque, vereda Marilandia, vía Santuario; 2.400 m; 8 de septiembre, 2011, B. Moncada 4820 (UDBC, holotipo). (Figura 9)

Descripción. Fotobionte primario cianobacteria. Pedúnculo ausente. Talo orbicular a suborbicular, hasta de $10 \mathrm{~cm}$ de diámetro, medianamente ramificado, con 3-5 ramificaciones por $5 \mathrm{~cm}$ de radio, ramificación politómica. Lóbulos suborbiculares, horizontales a ascendentes, imbricados, planos a levemente involutos, con los ápices redondeados, involutos, márgenes enteros a levemente crenados, no engrosados; entrenudos de los lóbulos de 6-8 mm de largo, (5-)7-13(20) $\mathrm{mm}$ de ancho, papiráceos, frágiles. Superficie superior lisa a levemente escrobiculada a foveolada (punteadoimpresa), de color gris verdoso cuando fresco, gris azul a marrón grisáceos en el herbario, brillante, con la línea marginal marrón; superficie glabra, sin papilas, sin pruina, con máculas irregulares diminutas, blancas. Cilios escasos a abundantes, simples a fasciculados, blancos, hasta de $0,5 \mathrm{~mm}$ de largo. Apotecios no observados. Propágulos vegetativos presentes, escasos a abundantes, en forma de isidios, principalmente laminares, dispersos, ramificados desde la base, coraloides, verticales, hasta de 0,3 $\mathrm{mm}$ de largo y 0,05 $\mathrm{mm}$ de ancho, más pálidos que el talo, de color gris pálido, opacos,

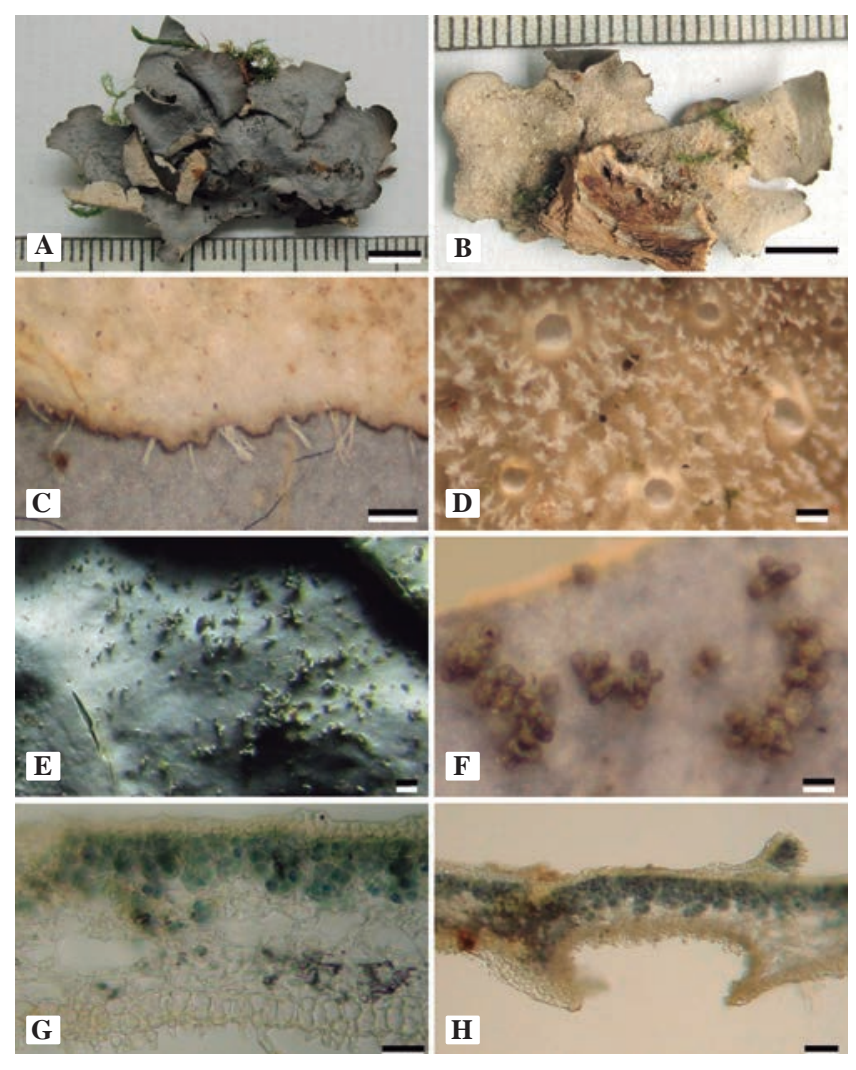

F igura 9. Sticta plumbeociliata. A. Vista dorsal del talo. B. Vista ventral del talo. C. Detalle de los cilios blancos. D. Detalle de las cifelas y del tomento ventral. E-F. Detalle de los isidios laminares. G. Anatomía del talo. H. Detalle de la cifela. Escala: A-B $=5 \mathrm{~mm}$, $\mathrm{C}-\mathrm{E}=0,5 \mathrm{~mm}, \mathrm{~F}=0,1 \mathrm{~mm}, \mathrm{G}-\mathrm{H}=100 \mu \mathrm{m}$ 
en sección transversal redondos, cilíndricos con los ápices engrosados, no globulares; pedúnculo si presente, cilíndrico a levemente aplanado en isidios viejos, sin cifelas. Médula laxa, de color blanco, $\mathrm{K}-\mathrm{a} \mathrm{K}+$ levemente amarillo pálido, $\mathrm{C}-$, $\mathrm{KC}+$ amarillo pálido, $\mathrm{P}-$. Superficie inferior lisa a levemente ondulada, de color blanco con una franja marginal de color marrón claro. Tomento ventral principal denso, ausente hacia el margen, grueso, más delgado hacia el margen, esponjoso, suave, de color blanco a beis hacia el centro. Tomento ventral secundario pubescente, claro. Rizinas ausentes. Cifelas abundantes, 41-60 por $\mathrm{cm}^{2}$ hacia el centro del talo y 61-100 por $\mathrm{cm}^{2}$ hacia el margen, dispersas, redondeadas, urceoladas con poro ancho, erumpentes a prominentes, abajo del nivel del tomento, con el margen involuto a levemente erecto de color blanco, sin tomento; poro de $(0,25-) 0,5-0,7(-1) \mathrm{mm}$ de diámetro hacia el centro del talo; membrana basal pubescente, de color blanco, $\mathrm{K}+$ amarillo pálido, $\mathrm{C}-, \mathrm{KC}+$ amarillo pálido, $\mathrm{P}-$. Picnidios no observados.

Corteza superior paraplectenquimática, de 15-35 $\mu \mathrm{m}$ de grosor, homogénea, conformada por 2-3 capas de células, de 3-10 $\mu \mathrm{m}$ de diámetro, con la pared de $0,6-2,5 \mu \mathrm{m}$ de grosor y el lumen redondeado a isodiamétrico de 2,5-7 $\mu \mathrm{m}$ de diámetro Capa de algas de 30-45 $\mu \mathrm{m}$ de grosor, con las células de 7,5-12 $\mu \mathrm{m}$ de diámetro. Médula de 35-50 $\mu \mathrm{m}$ de grosor, con hifas de 2,5 $\mu \mathrm{m}$ de ancho, sin cristales. Corteza inferior paraplectenquimática, de $17-20 \mu \mathrm{m}$ de grosor, con 1-2 capas de células; células de 6-14 $\mu \mathrm{m}$ de diámetro, con la pared de $0,6-1,2 \mu \mathrm{m}$ de grosor. Tomento ventral principal de 80-280 $\mu \mathrm{m}$ de largo, en fascículos mayores de 20 hifas, hifas ramificadas, septadas con los ápices entrecruzados. Tomento ventral secundario de 5-25 $\mu \mathrm{m}$ de largo, solitario, hifas simples, septadas con los ápices libres. Cavidad de las cifelas de $80-110 \mu \mathrm{m}$ de alto; cifeloblastos sin papilas.

Etimología. Esta especie debe su nombre al color azul grisáceo de la superficie dorsal y los cilios blancos.

Distribución y ecología. Andes de Colombia. Se ha encontrado entre 1.750-3.430 m, en bosques andinos intervenidos, en lugares con intensidad lumínica baja a media. Se cuenta con registros de su presencia en las cordilleras Central y Oriental en las zonas de vida subandina y andina de la región andina colombiana. Crece sobre la corteza de árboles y arbustos en el sotobosque, generalmente asociada con especies de los géneros Microlejeunea, Hypnum, Frullania y Pterobryum.

Discusión. Esta especie con talos azul-grisáceos, fotobionte cianobacterial, isidios laminares y cilios blancos prominentes, se podría confundir en campo con algunas especies con las cuales comparte semejanzas morfológicas como Sticta cometiella. Esta última se diferencia por el color de los cilios y la presencia de un tomento secundario. También comparte semejanza morfológica con S. isidioimpressula (M oncada, et al., en preparación), la cual se diferencia por la superficie puncteado-impresa y los isidios aplanados mezclados con isidios cilíndricos.
Especímenes examinados. COLOMBIA. Antioquia: Municipio de Santa Rosa de Osos, carretera a San José de la Montaña, a dos horas de Medellín; 2.400 m; 10 de junio, 1998, Ma. I. Lopera 92 (COL). Cauca: Municipio de Popayán, Los Robles, Campus de la Fundación Universitaria, 15 Km hacia Timbío; 3.315 m; 20-21 de junio, 1986, H. Sipman, R. Velosa, et al. 33738 (B, COL). Municipio de Puracé, costado oriental, carretera La Plata-Puracé, $2 \mathrm{~km}$ al este de los termales de San Juan; 3.430 m; 4 de octubre, 1984, J. Aguirre \& H. Sipman 5923 (B, COL). Municipio de Silvia, camino entre Piendamó y Silvia, NE de Popayán; 2.130 m; 22 de junio, 1986, H. Sipman, R. Velosa, et al. 33777 (B, COL). Cundinamarca: Municipio de Chipaque, vereda Marilandia, vía Santuario; 2.400 m; 8 de Septiembre, 2011, B. Moncada 4784, 4820, 4841 (UDBC). Municipio de Facatativá, Valle del Río Dulce, a 10 km NO de Facatativá; 2.600 m; 1 de febrero, 1979, H. Sipman, et al. 10349 (COL, U). Municipio de Fómeque, Parque Nacional Natural Chingaza, embalse de Chuza; 2.600 m; 15 de octubre, 1988, H. Sipman \& J. Aguirre 27413 (B, COL). Municipio de La Calera, Parque Nacional Natural Chingaza, Monterredondo; $4^{\circ} 44^{\prime} \mathrm{N}$, 73 51' O; 2.600 m; 13 de abril, 2011, B. Moncada 4640 (UDBC). Municipio de San Francisco, vereda Sabaneta, proximidades de la quebrada Cueva Grande; 2.400 m; 17 de julio, 1986, H. Sipman, et al. $23599 b$ (B, COL); ibid.; 2.500 m; 17 de julio, 1986, H. Sipman, et al. 23602 (B, COL). Magdalena: Municipio de Santa Marta, Sierra Nevada de Santa Marta, costado suroriental, hoya del Río Donachuí, Cancurua; 3.000 m; 10-11 de octubre, 1959, J. Cuatrecasas y R. Romero 24728 (COL). Risaralda: Municipio de Pereira, SFF Otún Quimbaya, vereda La Suiza, alrededores del centro de visitantes; $2.130 \mathrm{~m}$; 4 de septiembre, 2003, $B$. Moncada \& R. Dávila 2071 (UDBC). Municipio de Santa Rosa de Cabal, $300 \mathrm{~m}$ al E de los termales de Santa Rosa; $2.000 \mathrm{~m}$; 27 de septiembre, 1985, J. Wolf 151 (B, COL); ibid.; 1.900 m; 16 de octubre, 1985, J. Wolf 221 (COL). Santander: Municipio de Charalá, Virolín, Cañaverales, cerca a la Finca Santa Helena; 3.400 m; 25 de octubre, 1988, H. Sipman \& J. Aguirre 27619 (B, COL). Cañaverales, cerca de Entrerríos; 1.750 m; 25 de octubre, 1998, H. Sipman \& J. Aguirre 27643 (B, COL). Tolima: Municipio de Ibagué, cuenca del Río Combeima, Finca El Silencio; 2.500 m; 23 de junio, 1985, J. Hernández, et al. 3116 (COL, US). Las Juntas, El Silencio; 2.500 m; 28 de junio, 2002, D. Moreno \& P. Hincapié 135b (COL).

\section{Clave para las especies del morfotipo fuliginosa presentes en Colombia}

1a Talo con isidios cilíndricos a levemente aplanados uniformemente coloreados 2

1b Talo con filidios dorsiventrales, superficie ventral generalmente blanca 16

2a Isidios arbusculares, pedúnculo de los isidios con cifelas; cifeloblastos con numerosas papilas 
2b Isidios simples a ramificados, no arbusculares, si pedúnculos presentes, éstos sin cifelas; cifeloblastos variables 4

3a Superficie dorsal pubescente-escabrosa; isidios hasta de $1 \mathrm{~mm}$ de altura, cilíndricos; pedúnculos de los arbúsculos sin tomento; cifelas hasta de $3,5 \mathrm{~mm}$ de diámetro

S. arbuscula

3b Superficie dorsal tomentosa-aracnoidea; isidios hasta de $2 \mathrm{~mm}$ de alto, redondeados a levemente espatulados; pedúnculo de los arbúsculos con tomento; cifelas no mayores a 2 mm de diámetro ...... S. arbusculotomentosa

4a Superficie dorsal total o parcialmente pubescente, hirsuta o tomentosa 5

4b Superficie dorsal glabra 8

5a Talos pequeños, hasta de $5 \mathrm{~cm}$ de diámetro, revolutos; cifeloblastos con abundantes papilas 6

5b Talos medianos a grandes hasta de $15 \mathrm{~cm}$ de diámetro, rara vez involutos; cifeloblastos sin papilas o si presentes, con $1-4$ papilas 7

6a Superficie pubescente aracnoidea, con papilas diminutas; cilios presentes (aunque escasos) S. ciliata

6b Superficie pubescente con tricomas hirsutos muy conspicuos, sin papilas; cilios ausentes S. minutula

7a Talos fuertemente faveolados, planos a revolutos; superficie dorsal tomentosa pubescente, isidios simples a levemente ramificados, hasta de 0,2 $\mathrm{mm}$ de longitud; cifelas planas

S. arachnofuliginosa

$7 \mathrm{~b}$ Talos escrobiculados a ondulados; superficie dorsal débilmente pubescente a glabra hacia el margen y con abundantes setas esponjosas hacia el centro del talo; isidios simples a coraloides, hasta $0,5 \mathrm{~mm}$ de longitud; cifelas urceoladas con poro ancho .... S. hirsutofuliginosa

8a Cilios escasos a abundantes 9

8b Cilios ausentes 12

9a Cilios negro-marrón, hasta de $1 \mathrm{~mm}$ de longitud; tomento secundario ausente S. cometiella

9b Cilios blanco a marrón, hasta de 0,5 mm de longitud; tomento secundario presente. 10

10a Isidios globulares a cilíndricos con los ápices globulares, simples a apicalmente ramificados, brillantes; talos marrón oscuro en ejemplares de herbario; cifeloblastos con una papila

S. globulifuliginosa

10b Isidios cilíndricos con los ápices no globulares, ramificados desde la base, opacos; talos grisáceos en ejemplares de herbario; cifeloblastos sin papilas 11

11a Cifelas rosadas, K+ rojo borgoña; talos subcoriáceos S. roseocyphellata 11b Cifelas blancas, K+ amarillo; talos papiráceos a subcoriáceos

S. plumbeociliata

12a Talos grandes, hasta de $15 \mathrm{~cm}$, con isidios que se desarrollan en el talo generando lobulillos, especialmente hacia el margen; apotecios siempre presentes; cifeloblastos con una papila

S. macrofuliginosa

12b Talos pequeños a medianos, no mayores de $10 \mathrm{~cm}$, con isidios que no se desarrollan en el talo; sin lobulillos; apotecios no observados; cifeloblastos variables ........ 13

13a Isidios corimbosos ("brocoliformes”) 14

13b Isidios simples, cilíndricos hinchados (como salchichas) a coraloides, nunca corimbosos 15

14a Talos medianos hasta de $10 \mathrm{~cm}$ de diámetro, gris verdoso, marrón hacia el margen; isidios altos, hasta de $2 \mathrm{~mm}$, opacos; médula $\mathrm{K}$ - tomento secundario ausente; cifeloblastos sin papilas

S. gallowayana

14b Talos pequeños hasta de $5 \mathrm{~cm}$ de diámetro, marrón oscuro homogéneo; isidios pequeños, hasta de 0,8 mm de altura, brillantes; médula $\mathrm{K}+$ amarillo naranja; tomento secundario aracnoide; cifeloblastos con una papila.

S. viviana

15a Isidios frágiles, alargados, bifurcados o cilíndricos hinchados (con forma de salchicha); superficie dorsal gris plomo, con papilas abundantes; superficie ventral blanca; cifeloblastos con una papila ..... S. aff. fuliginosa

15b Isidios robustos, globulares o cilíndricos, raras veces aplanados, superficie dorsal gris verdoso a marrón, papilas ausentes; superficie ventral amarillenta o crema; cifeloblastos sin papilas. S. maculofuliginosa

16a Talos palmeados, pedúnculo indistinto a largo de $1 \mathrm{~cm}$, propágulos de 2-3 mm de longitud. Médula K+ rosa a borgoña pálido. 17

16b Talos orbiculares, pedúnculo ausente, propágulos hasta de $1 \mathrm{~mm}$ de longitud. Médula $\mathrm{K}$ - a levemente amarilla 18

17a Cilios abundantes, negros; cifelas con poro de 0,25 a 2,5 $\mathrm{mm}$; tomento denso, escaso hacia el margen, cifelas con poro de 0,25 a $2,5 \mathrm{~mm}$

S. macrothallina (cianomorfo)

17b Cilios ausentes, cifelas con poro de 0,6 a $1,7 \mathrm{~mm}$, tomento escaso, ausente hacia el margen

S. neopulmonarioides (cianomorfo)

18a Médula y máculas de color blanco; cilios ausentes; tomento ventral secundario presente, pubescente; cifelas urceoladas con poro ancho, hasta de $2 \mathrm{~mm}$ de diámetro, margen de la cifela involuto a recto

S. phyllidiofuliginosa 
18b Médula y máculas de color amarillo; cilios escasos; tomento ventral secundario ausente, cifelas planas, hasta de $1 \mathrm{~mm}$ de diámetro, margen de la cifela indiferenciado S. jaguirreana

\section{Agradecimientos}

Este estudio se llevó a cabo en el marco del proyecto Neotropical Epiphytic Microlichens - An Innovative Inventory of a Highly Diverse yet Little Known Group of Symbiotic Organisms de la National Science Foundation de Estados Unidos (DE B 715660 The Field M useum; PI R. Lücking). Expresamos especial agradecimiento al programa Research Grants in Plant Systematics Call for 2013 de The International Association for Plant TaxonomyIAPT, por el apoyo en la realización del proyecto How many species of Sticta are there? Igualmente, agradecemos a la Universidad Distrital Francisco José de Caldas por el apoyo en el Herbario Forestal Gilberto Emilio Mahecha Vega - Sección Criptógamas, así como a los curadores de los herbarios citados en este estudio.

\section{Conflicto de intereses}

Los autores declaran no tener ningún conflicto de intereses.

\section{Bibliografía}

Acharius, E . (1803). Methodus qua omnes detectos lichenes ad genera redigere tentavit. Estocolmo.

Aguirre-C., J . (2008). Catálogo de los líquenes de Colombia. (401-547) en: Rangel-Ch., J. O. (Ed.) Colombia Diversidad Biótica VI: Riqueza y Diversidad de los Musgos y Líquenes en Colombia. Bogotá: Instituto de Ciencias Naturales, Universidad Nacional de Colombia.

A ptroot, A., Sparrius, L. B., Lai, M. J . (2002). New Taiwan macrolichens. Mycotaxon. 84: 281-292.

B üdel, B ., M eyer, A., Salazar, N., Zellner, H., Z otz. G ., L ange, 0. L . (2000). Macrolichens of montane rain forests in Panama, Province Chiriqui. The Lichenologist. 32: 539-551.

Farkas, E. (2003). Contributions to the lichen flora of East Africa Pseudocyphellaria and Sticta. Acta Academiae Paedagogicae Sectio Biologiae. 24: 235-255.

Galloway, D. J. (1994). Studies on the lichen genus Sticta (Schreber) Ach. I. Southern South American species. The Lichenologist. 26: 223-282.

G alloway, D. J . (1997). Studies on the lichen genus Sticta (Schreber) Ach. IV. New Zealand species. The Lichenologist. 29: 105-168.

Galloway, D. J. (1998a). Studies on the lichen genus Sticta (Schreber) Ach. V. Australian species. Tropical Bryology. 15: $117-160$.

G alloway, D. J . (1998b). Edvard Vainio and the family Lobariaceae, with special reference to the taxonomic history of Sticta. En: Marcelli, M.P. \& Ahti, T. (Eds.). Recollecting Edvard August Vainio. (61-84). São Paulo, Brazil: Companhia de Tecnologia de Saneamento Ambiental, Estado de São Paulo.
Galloway, D. J . (2001). Sticta. Flora of Australia. Volume 58a, Lichens. 3: 78-97.

Galloway, D. J . (2007). Flora of New Zealand Lichens (2nd ed.). Lincoln. Manaaki Whenua Press.

Gyenik, V.K. (1931). De Stictacaeis nonnullis. In Repertorium specierum novarum regni vegetabilis. 29: 292-300

Hue, A.M . (1901). Tribus XXII Sticteae. Lichens Extra Europaei, a pluribus collectoribus ad museum parisiense missi. Nouv. Archiv. Du Museum, Ser. 4, vol. III p. 22-102

J oshi, M . \& Awasthi, D. D. (1982). The lichen family Stictaceae in India and Nepal. Biological Memoirs. 7: 165-190.

Lumbsch, H.T. (2002) Analysis of phenolic products in lichens for identification and taxonomy. In: Kranner I, Beckett RP, Varma AK (Ed). Protocols in Lichenology. Culturing, Biochemistry, Ecophysiology and Use in Biomonitoring (281-295). Springer, Berlin \& Heidelberg.

L uteyn, J . L . (1999). Páramos: A checklist of plant diversity, geographical distribution, and botanical literature. New York. The New York Botanical Garden Press.

Mackay, J . T. (1836). Flora Hibernica. Curry. Dublin.

M cDonald, T., M iadlikowska, J ., L utzoni, F. (2003). The lichen genus Sticta in the Great Smoky Mountains: A phylogenetic study of morphologial, chemical, and molecular data. The Bryologist. 106: 61-79.

Moncada B. (2012). El género Sticta en Colombia, Taxonomía, Ecogeografía e Importancia. (Tesis doctoral). Universidad Nacional de Colombia. Bogotá.

M oncada, B ., A guirre, J ., L ücking, R . (2014). Ecogeografía del género Sticta (Ascomycota liquenizados: Lobariaceae) en Colombia. Revista de Biología Tropical. 62: 266-281.

Moncada, B., C oca, L. F., Lücking, R. (2013c). Neotropical members of Sticta (lichenized Ascomycota: Lobariaceae) forming photosymbiodemes, with the description of seven new species. The Bryologist. 116 (2): 169-200.

M oncada, B. \& L ücking R. (2012b). Ten new species of Sticta and counting: Colombia as a hot spot for unrecognized diversification in a conspicuous macrolichen genus. Phytotaxa. 74: 1-29.

M oncada, B ., L ücking, R ., B etancourt, L . (2013a). Phylogeny of the Lobariaceae (lichenized Ascomycota: Peltigerales) with a reappraisal of the genus Lobariella. The Lichenologist. 45: 203-263.

Moncada, B., Lücking, R., C oca, L. F. (2013d). Six new apotheciate species of Sticta (lichenized Ascomycota: Lobariaceae) from the Colombian Andes. The Lichenologist. 45: 635-656.

Moncada, B., Lücking, R., Suárez, A. (2013b). Molecular phylogeny of the genus Sticta (lichenized Ascomycota: Lobariaceae) in Colombia. Fungal Diversity. 64 (1): 205-231.

Orange, A., James, P.W., White, FJ . (2001) Microchemical Methods for the Identification of Lichens. British Lichen Society, London.

Purvis, W. (2000). Lichens. The Natural History Museum. London, Life Series. 
Sipman, H. J. M, Aguirre-C., J., Rangel-Ch., J . O. (2000). Líquenes. En: Rangel-Ch. (Ed.) Colombia Diversidad Biótica III: La Región de Vida Paramuna. Bogotá: Edit. Unilibros, Universidad Nacional de Colombia.

Sipman, H. J . M ., Hekking, W., Aguirre-C ., J . (2008). Checklist of lichenized and lichenicolous fungi from Colombia. Biblioteca José Jerónimo Triana No. 20. Bogotá: Instituto de Ciencias Naturales, Facultad de Ciencias, Universidad Nacional de Colombia.

Stizenberger, E. (1895). Die Grübchenflechten (Sticta) und ihre geographische Verbreitung. Flora. 81: 88-150.

Suárez, A. \& Lücking, R. (2013) Sticta viviana (lichenized Ascomycota: Peltigerales: Lobariaceae), a new species from Colombian páramos. The Lichenologist. 45: 153-157.
Swinscow, T. D. V. \& K rog, H. (1988). Macrolichens of East Africa. London. British Museum (Natural History).

Takahashi, K., Wang, L .-S., Tsubota, H., Deguchi, H. (2006). Photosymbiodemes Sticta wrightii and Dendriscocaulon sp. (lichenized Ascomycota) from Yunnan, China. Journal of the Hattori Botanical Laboratory. 100: 783-796.

Tønsberg, T. \& Goward, T. (2001). Sticta oroborealis sp. nov. and other Pacific North American lichens forming dendriscocauloid cyanotypes. The Bryologist. 104: 12-23.

Vainio, E . A . \& L iebmann, F. M . (1926). Lichenes mexicani a FM Liebmann annis 1841-1843 collecti, in Museo hauniensi asservati. H. Hagerup’s Boghandel. Dansk Botanisk Arkiv. 4 (11): 1-25. 